\title{
La adaptación del contrato como medio de tutela precontractual en el Código Civil chileno
}

\author{
Patricia Verónica López Diaz*
}

\section{RESUMEN}

El propósito de este artículo es abordar la adaptación del contrato como medio de tutela precontractual a partir de su actual configuración en el soft law y determinar si es posible identificar supuestos en que nuestro Código Civil la admita, ensayando una relectura de sus disposiciones con la finalidad de incardinarlo en el sistema de protección precontractual del acreedor y obtener así la conservación del contrato por circunstancias acaecidas en dicha fase.

Tutela precontractual - adaptación del contrato - error vicio

\section{Adaptation of a contract as pre-contractual remedy in the chilean civil}

\begin{abstract}
The purpose of this article is to address the adaptation of the contract as a means of pre-contractual protection from its current configuration in the soft law and determine whether it is possible to identify cases in the Chilean Civil Code through a reinterpretation of its provisions in order to incorporate in the system pre creditor protection and conservation obtain the contract due to circumstances ocurring at that stage.
\end{abstract}

Pre-contractual protection - adaptation of the contract - mistake

* Licenciada en Ciencias Jurídicas y Sociales, Universidad Adolfo Ibáñez. Doctora en Derecho, Pontificia Universidad Católica de Valparaíso. Profesora de Derecho Civil, Universidad de Valparaíso. El presente artículo forma parte del Proyecto FONDECYT de Iniciación N ${ }^{\circ}$ 11150423: "Hacia la articulación de un sistema de medios de tutela por responsabilidad precontractual en el Código Civil Chileno" del que la autora es investigadora responsable.

Artículo recibido el 8.11.2016 y aceptado para su publicación en este número el 5.1.2018. 


\section{INTRODUCCIÓN}

partir del movimiento de modernización de obligaciones y contratos, que comen-
zó a plasmarse en diversos instrumentos, así como los Principios UNIDROIT
(PICC), los Principios de Derecho Contractual Europeo (PECL), la Propuesta de Modernización del derecho de obligaciones y contratos española (PME), el Marco Común de Referencia (DCFR), el Borrador de los Principios Latinoamericanos de Derecho de los Contratos (PLDC), la Propuesta de Código Civil relativa a los Libros Quinto y Sexto elaborada por la Asociación de profesores de Derecho Civil español de 2016 (PAPDC) y la Ordenanza N 2016-131 de 10 de febrero de 2016 que modificó el Code en materia de obligaciones y contratos en general ${ }^{1}$, ha resurgido la inquietud de la doctrina nacional por abordar la fase precontractual.

En efecto, durante la última década, diversos autores han analizado las consecuencias derivadas de la ruptura injustificada de las negociaciones, la existencia de deberes precontractuales de lealtad, información, confidencialidad, conservación y custodia, la vinculación entre la violación de estos y la validez del contrato ${ }^{2}$, extendiendo su análisis a la Ley 19.496 de 1997 sobre Protección de los Derechos de los Consumidores para explorar el rol de la publicidad en los negocios de consumo, los ilícitos precontractuales y el suministro de información como técnica de protección ${ }^{3}$. Incluso, recientemente, se ha sugerido articular la nulidad, indemnización de daños y adaptación del contrato en

${ }^{1}$ Ordenanza que comenzó a regir el $1^{\circ}$ de octubre de 2016. Los PICC regulan este tópico, pero en forma menos detallada que los otros instrumentos contractuales, como se desprende de los artículos 2.15, 2.16, 3.6., 3.10 y 3.18. Una regulación más completa se aprecia en los artículos 4.105, 4.106 a 4.109 y 4.112 a 4.119 de los PECL y se repite en los artículos 7:203, 7:204, 7:207, 7:209 a 7:216 del Capítulo VII del Libro II DCFR. Otro tanto se advierte en los artículos 1245 y 1296 a 1314 de la PME y 9 a 11,37 y 41 a 48 de los PLDC.

${ }^{2}$ Entre otros, Rosende, H., Algunas consideraciones sobre la responsabilidad precontractual, Ediciones Universitarias de Valparaíso, 1979, Barros, E., Tratado de responsabilidad civil extracontractual, Editorial Jurídica de Chile, Santiago, 2006, pp. 1014 a 1041, Zuloaga, I.M., Teoría de la responsabilidad precontractual. Aplicaciones en la etapa de la formación del consentimiento, Editorial LexisNexis, Santiago, 2006, Barrientos, M., Daños y deberes en las tratativas preliminares de un contrato, Santiago, Editorial LegalPublishing, 2008, pp. 73-109, De la Maza, I., "Tipicidad y atipicidad de los deberes precontractuales de información”, en Revista de Derecho Pontificia Universidad Católica de Valparaíso, Vol. 34, julio, 2010, pp. 75-99, Celedón, R.; Silberman, P., Responsabilidad precontractual por ruptura de negociaciones contractuales, Editorial Jurídica de Chile, Santiago, 2010.

${ }^{3}$ Véase Momberg, R., "El rol de la publicidad en la etapa precontractual de los negocios de consumo y su relación con el principio de buena fe”, en Corral, H.; Rodríguez, M., Estudios de Derecho Civil II, Editorial Lexis Nexis, Santiago, 2007, pp. 593-608, Rodríguez, M.S., "Responsabilidad precontractual en la Ley 19.496 de 1997 sobre Protección de los Derechos de los Consumidores”, en Domínguez, C.; González, J.; Barrientos, M.; Goldenberg, J., Estudios de Derecho Civil VIII, Editorial LegalPublishing, Santiago, 2013, pp. 493-501, De la Maza, I., "El suministro de información como técnica de protección de los consumidores: los deberes precontractuales de información", en Revista de Derecho Universidad Católica del Norte, año 17 , $\mathrm{N}^{\circ}$ 2, 2010, pp. 21-52; Pinochet, R., "Obsolecencia programada y protección del derecho a la información en la Ley N 19.496 de Protección de los Consumidores”, en Vidal, A.; Severin, G.; Mejías, C., Estudios de Derecho Civil X, Editorial Thomson Reuters, La Ley, Santiago, 2015, pp. 397-411. 
torno a un supuesto aglutinador único, con el propósito de permitir al acreedor diseñar de mejor forma su estrategia de protección frente a anomalías o disconformidades suscitadas en dicha fase ${ }^{4}$.

Es precisamente en una arista de este último tópico en la que queremos detenernos. Y es que resulta indiscutido que la nulidad, en cualquiera de sus modalidades, y la indemnización de daños, en ciertos y determinados supuestos, constituyen medios de tutela precontractuales, cuya procedencia y efectos han sido tratados, con mayor o menor intensidad, por la doctrina nacional ${ }^{5}$. Sin embargo, hasta la fecha, la adaptación del contrato no ha sido mayormente explorada en esta sede ${ }^{6}$, a diferencia de lo que ha acontecido en el derecho comparado ${ }^{7}$, ni cotejada con la adaptación derivada de causales sobrevenidas a la negociación y celebración del contrato, como la imprevisión y la rebaja del precio.

Un análisis preliminar podría arrojar que como la adaptación del contrato se encuentra regulada en los PICC, PECL, PME, PLDC y, recientemente, en la PAPDC, constituiría una institución foránea que no resulta aplicable en ordenamientos jurídicos como el nuestro. Y es que tales Principios o Propuestas de modificación constituyen el resultado de un intento de armonización entre el Civil Law y el Common Law en materia de obligaciones y contratos, cuyo propósito es alcanzar una normativa transfronteriza

\footnotetext{
${ }^{4}$ López, P.V., "Por la articulación de un sistema de medios de tutela precontractual en el Código Civil chileno", en Estudios de Derecho Civil XII, en prensa.

${ }^{5}$ En lo que concierne a la indemnización véase Rosende, H., op. cit., pp. 59-100, Rodríguez, P., Inexistencia y nulidad en el Código Civil. Teoría Bimembre de la Nulidad, Editorial Jurídica de Chile, Santiago, 1995, pp. 296-303, Barros, E., op. cit., pp. 1013-1041, Zuloaga, M., op. cit., Celedón, R.; Silberman, P., op. cit., Baraona, J., La nulidad de los actos jurídicos: consideraciones históricas y dogmáticas, Editorial Pontificia Universidad Javeriana-Ibáñez, Bogotá, 2012, pp. 83-101, Pinochet, R. y Concha, R., "Las prestaciones mutuas en caso de nulidad de contrato: carácter indemnizatorio o restitutorio en el derecho civil chileno", en Revista de Derecho Privado Universidad Externado de Colombia, Vol. 28, enero-junio 2015, pp. 129-152 y López, P.V., "Los supuestos y el alcance de la indemnización de daños como medio de tutela precontractual en el Código Civil chileno y su eventual confluencia con la indemnización por incumplimiento”, en Revista Ius et Praxis, en prensa. En lo referente a la nulidad, Alessandri, A., La nulidad y la rescisión en el derecho civil chileno, Tomo II, Editorial Jurídica de Chile, $3^{\mathrm{a}}$ ed., Santiago, 2008, Rodríguez, op. cit. y Baraona, op. cit.

${ }^{6}$ Excepcionalmente lo trata De la Maza, a propósito de su regulación en los PECL (De la Maza, I. "Libertad y seguridad: el tratamiento del error en los Principios de Derecho Contractual Europeo", en Revista chilena de derecho, Vol. 34, No 3, diciembre, 2007, pp. 511-513) y López lo esboza como medio de tutela que se articula en un sistema precontractual, abordándolo muy preliminarmente (López, P.V., "Por la articulación de un sistema...”., op. cit.).

${ }^{7}$ Principalmente Díez-Picazo, L., Roca, E. y Morales, A., Los Principios del Derecho Europeo de Contratos, Editorial Civitas, Madrid, 2002, pp. 226-227, Morales, A., "Validez del Contrato”, en Cámara, S. (coord.), Derecho Privado Europeo, Madrid, Editorial Colex, 2003, pp. 371-397, Morales, A., “¿Es posible construir un sistema precontractual de remedios? Reflexiones sobre la Propuesta de Modernización del Derecho de Obligaciones y Contratos en el marco del Derecho europeo”, en Albiez, K. (dir.), Palazón, M. L. y Méndez, M.M. (coords.), Derecho Privado Europeo y Modernización del Derecho Contractual en España, Editorial Atelier, Barcelona, 2011, pp. 400-422 y Gaspar, S., "Formación de la voluntad contractual, vicios del consentimiento y remedios”, en Parra, M.A., Negociación y perfección de los contratos, Editorial Thomson Reuters Aranzadi, Navarra, 2014, pp. 301-304.
} 
uniforme europea o la unificación del derecho privado latinoamericano ${ }^{8}$, según el caso, y, por lo mismo, en ocasiones, se erigen sobre postulados extraños a nuestro Código.

Sin embargo, estimamos que existen, al menos, cinco argumentos que justifican abordarla en nuestra dogmática. En primer lugar, develará si puede ensayarse su construcción en el Código Civil chileno a partir de disposiciones que así lo permitan y, en tal evento, determinar si resulta más conveniente al acreedor la tutela precontractual o contractual, en aquellos supuestos en que pueda inclinarse por una u otra. De otro lado, el profuso análisis y desarrollo de este tópico en sede contractual, a partir de la teoría de la imprevisión o alteración sobrevenida de las circunstancias ${ }^{9}$ y, recientemente, a propósito de la rebaja del precio ${ }^{10}$, contrasta con la precariedad de su estudio en sede precontractual, lo que evidencia la disparidad en el tratamiento de los medios de tutela precontractuales y contractuales y la relevancia del esfuerzo dogmático que proponemos. Permite constatar además que, al menos, en lo que concierne a los vicios del consentimiento, no existe tan solo un problema de voluntad defectuosa sino de organización de los intereses contractuales que, eventualmente, puede traducirse en un contrato dañoso ${ }^{11}$, toda vez que, adaptado el contrato, y eliminado los daños derivados de aquel, desaparece el interés del contratante perjudicado en desvincularse de este. Por otra parte, amplía el ámbito de aplicación del principio de conservación del contrato o favor contractus que, hasta ahora, estaba relegado a instituciones como la nulidad parcial, la conversión del acto nulo, la confirmación de la nulidad relativa, la teoría de la imprevisión, la rebaja del precio y que, en el último tiempo, se ha admitido progresivamente a propósito de la autonomía de la indemnización de daños por incumplimiento contractual ${ }^{12}$. Finalmente, revela que la nulidad no es el único medio de tutela precontractual, sino el más radical.

${ }^{8}$ Una adecuada síntesis de este propósito y su estado actual en Ferrante, A., “QQuimera o Fénix? El recorrido europeo y latinoamericano hacia un derecho común de contratos”, en Revista de Derecho Privado, Universidad Externado de Colombia, Vol. 30, 2016, enero-junio, pp. 107-127. En cambio, la Ordenanza $\mathrm{N}^{\circ}$ 2016-131 de 10 de febrero de 2016 que modificó el Code no la menciona ni contempla las causales contenidas en tales instrumentos contractuales.

${ }^{9}$ Para una visión panorámica de la doctrina nacional que se ha abocado al estudio de este tópico véase De la Maza, I. "Las consecuencias de la alteración sobrevenida de las circunstancias”, en Figueroa, G., Barros, E., Tapia, M., Estudios de Derecho Civil VI, Editorial AbeledoPerrot-LegalPublishing, Santiago, 2011, notas 18 y 19, pp. 304-305, a los que deben agregarse Momberg, R., Teoría de la imprevisión: la necesidad de su regulación legal en Chile, Revista Chilena de Derecho Privado N $\mathrm{N}^{\circ}$ 15, diciembre, 2010, pp. 29-64 y López, C., Revisión de los contratos por causas sobrevinientes, Editorial Metropolitana, $3^{\text {a }}$ ed., Santiago 2014.

${ }^{10}$ Prado, P., "La cuantificación de la rebaja del precio en la acción quanti minoris", en Revista Ius et Praxis, año 21, No 1, junio, 2015, pp. 617-650.

${ }^{11}$ Morales, A., “¿Es posible construir un sistema precontractual de remedios...”., op. cit., p. 413.

12 Se trata de uno de los posibles efectos de la autonomía de la indemnización, pues también puede producir la extinción del contrato, dependiendo de la entidad del incumplimiento, la forma de ejecución y la cuantía de la indemnización solicitada. Véase López, P.V., La autonomía de la indemnización de daños por incumplimiento de un contrato bilateral en el Código Civil Chileno, Editorial Thomson Reuters LegalPublishing, Santiago, 2015, pp. 344-356. 
Por consiguiente, es necesario examinar si existe algún supuesto en que el Código Civil chileno admita la adaptación del contrato, o en su defecto, ensayar una propuesta que permita su incardinación, a partir de las normas contenidas en él. Para alcanzar tal objetivo se seguirá el esquema que referimos a continuación: en primer lugar, se expondrán los supuestos en que tiene lugar la adaptación del contrato en el soft law y se indagará si es posible identificarlos o reconducirlos a instituciones o hipótesis contenidas en nuestro Código Civil (II). A continuación se abordarán las modalidades que puede adoptar este medio de tutela en el Código Civil y el alcance de la protección que dispensan al acreedor (III). Seguidamente se especificará si existen supuestos en que pueda confluir la adaptación precontractual y contractual y, en el evento que el acreedor decida optar entre ambas, determinar cuál es más adecuada (IV). Examinados tales tópicos, se formularán las conclusiones (V).

\section{LA ADAPTACIÓN DEL CONTRATO EN EL SOFT LAW: LOS SUPUESTOS DE ERROR VICIO Y EL PROVECHO EXCESIVO O VENTAJA INJUSTA O DESLEAL}

Una revisión del articulado de determinados instrumentos contractuales de soft law en materia de obligaciones y contratos, no solo permite constatar que actualmente existe, en el ámbito europeo y latinoamericano, una especial preocupación por preservar el equilibrio prestacional originario o congénito mediante la nulidad contractual o de la indemnización derivada de aquella, ocasionada por ruptura injustificada de las tratativas preliminares, infracción de los deberes precontractuales de lealtad, confidencialidad o información y pérdida de la facultad de anular el contrato ${ }^{13}$, sino que también se admite la posibilidad de renegociar el contrato a partir de determinadas causales que tienen lugar al momento de su celebración.

A esta rectificación del contrato vigente, por circunstancias acaecidas en la fase precontractual, que se reconducen específicamente al error vicio, provecho excesivo, ventaja desleal o explotación injusta y evidencian la intención de recomponer la simetría prestacional inicial, conservándolo con un contenido diverso, se ha denominado adaptación del contrato. Al menos esta es la nomenclatura acuñada por los artículos 4:105 y 4:109 (3) de los PECL, que aluden, respectivamente, a la adaptación del contrato por error unilateral o compartido y al beneficio excesivo o ventaja injusta, II.-7:203 y II.-7:207 (3) del DCFR que replican aquellos y el 527-14 de PAPDC. A ellos se agregan los artículos 3.2.10 y 3.2.7 de los PICC a propósito de la pérdida del derecho a anular el contrato y la excesiva desproporción y 30 y 37 de los PLDC, relativos al impedimento para alegar error y a la excesiva desproporción que, según veremos, indirectamente la recogen.

${ }^{13}$ En lo que concierne a este último supuesto véanse los artículos 4:117(2) de los PECL y II.7:214 del DCFR. 
Esta figura también se advierte en el Código Civil italiano, pues el artículo 1432, bajo el epígrafe Mantenimento del contratto rettificato, establece que la parte que incurrió en error no puede demandar la nulidad del contrato, si antes que experimente perjuicio, la otra le ofrece mantenerlo conforme al contenido y modalidad que ella tuvo la intención de concluir. Otro tanto acontece con el Código Civil portugués, cuyo artículo 248 regula la "validación del negocio", prescribiendo que la anulación por error no procede si el destinatario de la declaración acepta el negocio como el declarante quería. Un fenómeno similar se aprecia en el artículo 269 del Código Civil y Comercial argentino, toda vez que dispone que, la parte que incurre en error, no puede solicitar la nulidad del acto, si la otra ofrece ejecutarlo con las modalidades y el contenido que aquella entendió celebrar. A ellos podría agregarse el Código español, si se aprueba la PME o la PAPDC y se incorpora, según el caso, el artículo 1301 o el artículo 527-14 que, como veremos, la regula en términos muy similares a los instrumentos contractuales de soft law.

La adaptación del contrato, así concebida, constituye una novedad en la teoría general del contrato y en el sistema de protección del acreedor, pues, hasta ahora, ella estaba restringida a causales acaecidas con posterioridad a su celebración, como la imprevisión o alteración sobrevenida de las circunstancias y la rebaja del precio, de modo que existiría una nueva manifestación del principio de equilibrio originario ${ }^{14}$. Y es que, a diferencia de la nulidad, no aboga por la aniquilación del contrato ni implica, consecuencialmente, su desaparición, como acontece con la indemnización de daños derivada de aquella, ocasionada por la ruptura injustificada de las tratativas preliminares o asociada a los vicios redhibitorios si, en este último supuesto, el acreedor decide inclinarse por esta modalidad de ejercicio.

Por otro lado, confirma la premisa en la que cada sistema de tutela persigue satisfacer, preferentemente, un solo interés, identificándose este con el positivo en el sistema contractual $^{15}$ y con el negativo en el precontractual. En efecto, así como la rebaja del precio permite reconfigurar la equivalencia subjetiva del contrato, a partir del verdadero estado de la cosa, la adaptación alcanza esta finalidad, considerando el contenido que una o ambas partes, según el caso, creyeron que tenía el contrato o este debió tener

${ }^{14}$ Acerca de otras manifestaciones de este principio en nuestro Código Civil véase López, P.V., "El principio de equilibrio contractual en el Código Civil chileno y su particular importancia como fundamento de algunas instituciones del moderno derecho de las obligaciones en la dogmática nacional", en Revista Chilena de Derecho Privado, No 25, diciembre, 2015, pp. 131-144.

${ }^{15}$ De hecho, actualmente la dogmática nacional, siguiendo a la comparada, ha desestimado progresivamente el efecto retroactivo de la resolución por incumplimiento, postulando que este se produce hacia el futuro, bajo la modalidad de liquidación del contrato, lo que permite sostener que, al igual que el cumplimiento y la indemnización, está orientada a satisfacer el interés positivo (Pizarro, C., "Contra el efecto retroactivo de la resolución por incumplimiento contractual", en Elorriaga, F. (coord.), Estudios de Derecho Civil VII, Editorial AbeledoPerrot-LegalPublishing Thomson Reuters, Santiago, 2012, pp. 457-460, Contardo, J. I., Indemnización y resolución por incumplimiento, Editorial Thomson Reuters-La Ley, Santiago, 2015, pp. 317-334, Alcalde, J., "Bases para una sistematización de los efectos de la resolución por incumplimiento", en Vidal, A.; Severin, G.; Mejías, C. (edits.), Estudios de Derecho Civil X, Editorial Thomson Reuters-La Ley, Santiago, 2015, pp. 591-594 y Mejías, C.C., "Una revisión crítica de los efectos de la resolución por incumplimiento y una propuesta de solución”, Revista Ius et Praxis año 22, No 1 (2016), pp. 271-322. 
si no hubiere existido error vicio o provecho excesivo. Solo excepcionalmente existen supuestos en que un medio de tutela precontractual se encuentra a medio camino entre el interés negativo y positivo. Piénsese en la indemnización por pérdida de la facultad de anular el contrato que tiene lugar si se renuncia a ella o la acción de nulidad ha prescrito, toda vez que comprende la diferencia entre la posición en que el contratante informado incorrectamente se encuentra actualmente y aquella en que estaría si se le hubiera proporcionado la información correcta, agregándose las pérdidas que superen esa diferencia. Otro tanto se advierte en la indemnización derivada de declaraciones falsas o inexactas que no constituyen error ${ }^{16}$.

Además, por regla general, constituye un límite a la procedencia de la nulidad tratándose del error unilateral, debido a que, solicitada la adaptación del contrato, el perjudicado pierde el derecho de anularlo y queda sin efecto toda acción anterior que haya entablado en este sentido. Así lo señalan expresamente los artículos 4:105 (2) de los PECL y 3.2.10 (2) de los PICC, 1298.4 de la PME, idea que también recoge el artículo 30 de los $\mathrm{PLDC}^{17}$. Esta restricción ciertamente evidencia que, al igual que la nulidad, forma parte de una ordenación de medios de tutela aglutinados en torno a un común denominador que, por lo mismo, permite al acreedor optar entre uno u otro, pero en ningún caso acumularlos, toda vez que si bien pretenden satisfacer el interés negativo, sus efectos son diversos. La nulidad aniquila el contrato, en tanto, la adaptación permite que este subsista y, como constataremos, la primera procura satisfacer por vía indirecta el interés del perjudicado, en tanto, la segunda, obtiene directamente dicho propósito, procurando la conservación del contrato. De otro lado, si los daños sufridos con ocasión del error o el provecho excesivo no quedaran absorbidos por la adaptación del contrato, el perjudicado puede solicitar la indemnización, advirtiéndose nuevamente una interrelación entre los medios de tutela precontractual en torno a un elemento articulador que permite al acreedor transitar entre uno a otro, concurriendo sus requisitos de procedencia.

\section{El error vicio del consentimiento}

El primer supuesto de adaptación del contrato se encuentra regulado en los artículos 4:105 de los PECL, II.-7:203 del DCFR, 1298.4 de la PME y 527-14 de la PAPDC, refiriéndose los dos primeros al error que vicia el consentimiento, sea que uno de los contratantes (unilateral) o ambos (compartido) hayan incurrido en él y, los dos segundos, exclusivamente al error unilateral. No contemplan, en cambio, como causales, la fuerza o el dolo, ya que es muy probable que si concurren tales vicios del consentimiento, el

${ }^{16}$ Véanse, respectivamente, los artículos 4:117(2) de los PECL y II.7:214 del DCFR y 4:106 de los PECL. Un análisis dogmático de tales supuestos en López, P.V., "Los supuestos y el alcance de la indemnización de daños...", op. cit.

${ }^{17}$ Distinto es el caso en los artículos 248 del Código Civil portugués y 1183 del Code (después de la Ordenanza N N $^{\circ} 2016-131$ de 10 de febrero de 2016), ya que disponen que una parte puede proponer a la víctima del error la opción por la ejecución del contrato en los términos que ella había comprendido al momento de su ejecución. 
contratante perjudicado no tenga ningún interés en mantener ni en adaptar el contrato. A ellos se agregan, como examinaremos a continuación, los artículos 3.2.10 de los PICC y 30 de los PLDC, que si bien no aluden expresamente a la adaptación del contrato, regulan la pérdida del derecho que tiene el legitimado para anularlo si la otra parte declara su voluntad de cumplirlo o lo cumple en los términos que aquel lo entendió, describiendo así un supuesto de error unilateral, y agregando que, en ese caso, se considerará perfeccionado el contrato en tales términos.

En lo que concierne al error unilateral, la modalidad es extrajudicial y tiene lugar si uno de los contratantes incurre en error, supuesto en el cual se faculta al otro a impedir la impugnación del contrato por nulidad, cumpliéndolo o manifestando su voluntad de cumplirlo, sin demora excesiva, en el sentido que lo entendió quien lo padece, una vez que sea informado de los términos en que dicho contratante creía que este se había celebrado. En tal hipótesis el errans no podría rechazar la propuesta de adaptación si no le perjudica, pues tal negativa sería contraria a la buena fe y constituiría un abuso del derecho, develando que tal error no era esencial o excusable ${ }^{18}$. No se contempla, en cambio, la facultad que este solicite la adaptación ${ }^{19}$, sino que solo puede beneficiarse de ella en la medida que exista error compartido.

Piénsese en un contratista que debe instalar los suelos de un gran edificio, pero comete un error al calcular el trabajo para ejecutar la obra y pretende anular el contrato, invocando este argumento, y la otra parte, para evitar la nulidad, le propone adecuar la obra al trabajo calculado y liberarlo de realizar el trabajo extra (no tenido en cuenta), sin reducir el precio pactado por su servicio ${ }^{20}$. En este caso resulta claro que la adaptación permitirá satisfacer el interés del contratante que padeció el error, de modo tal que solicitar la nulidad del contrato no se justifica. De allí que los artículos 4:105 (2) de los PECL, II.-7:203 (2) del DCFR, 3.2.10 (2) de los PICC, 1298.4 de la PME y 527-14 (2) de la PAPDC establezcan que el cumplimiento por parte del contratante en los términos que el errans lo hubiera entendido o la manifestación de su voluntad en tal sentido, acarrea la pérdida del derecho de anular el contrato y deja sin efecto toda acción anterior encaminada a tal propósito.

Con todo, algunos de estos preceptos contemplan un primer límite a la adaptación del contrato, indicando que procede antes que la víctima del error "haya alegado dicha anulabilidad y actúe en función de ella" (artículos 4:105 (2) de los PECL y II.-7:203

${ }^{18}$ Morales, A., El error en los contratos, Editorial Ceura, Madrid, 1988, p. 88 y Gaspar, S., op. cit., p. 302.

${ }^{19}$ Refiriéndose a esta omisión, Morales indica que podría integrarse este vacío entendiendo la adaptación como una indemnización in natura (Morales, A., “¿Es posible construir un sistema precontractual de remedios...?”., op. cit., p. 415). En contra, Pantaleón y Cuadrado postulan que tal planteamiento desconfiguraría dicha pretensión (Pantaleón, F., "Responsabilidad precontractual: propuestas de regulación para un futuro Código Latinoamericano de Contratos”, en: Anuario de Derecho Civil, Vol. 64, N 3, 2011, p. 924 , nota 27 y Cuadrado, C. "La responsabilidad precontractual en la reforma proyectada: ¿una ocasión perdida? (parte II)”, Revista Crítica de Derecho Inmobiliario, No 746, noviembre, 2015, p. 3024).

${ }^{20}$ Ejemplo propuesto en Lando, O.; Beale, H., Principios de derecho contractual europeo. Partes I y II (Traducc. Pilar Barres Benlloch, José Embid Irujo, Fernando Martínez Sanz), Colegios Notariales de España, Madrid, 2003, p. 352. 
(2) del DCFR) o antes que "ella proceda a obrar razonablemente de conformidad con la notificación de la anulación" (artículo 3.2.10 (2) de los PICC). En otras palabras, este medio de tutela debe intentarse si la adaptación aún es posible y no cuando el contratante que padeció error ya hubiera manifestado su voluntad de anular el contrato o realizado actos que supongan tal manifestación, como ocurrirá, respectivamente, si en el ejemplo de más arriba la empresa contrató a otro individuo para que realice la instalación del suelo que el primer contratista ejecutaría o celebró contratos incompatibles con aquel cuya nulidad se solicita ${ }^{21}$.

Lo cierto es que en el último tiempo se ha sostenido que esta modalidad de adaptación no constituiría un medio de tutela para quien incurre en el error, sino un mecanismo del que dispone el otro contratante para impedir la anulación del contrato, constituyendo una excepción que lo facultaría para preservarlo en los términos que entendió el errans. De otro lado, se ha postulado que, atendido que para que este último pueda exigir que el contrato se cumpla en los términos que lo ha entendido, es necesario que su representación subjetiva forme parte del contenido vinculante del contrato y esté garantizada por el otro contratante, estaremos ante un incumplimiento y, por consiguiente, fuera del sistema precontractual ${ }^{22}$.

Disentimos de este planteamiento, pues si bien para uno de los contratantes constituye una excepción, estimamos que, es el contratante que padeció el vicio, el que deberá decidir si acepta la propuesta de adaptación ofrecida por aquel, en la medida que no solo sea aún posible sino, como veremos luego, conveniente para él. En consecuencia, al menos para el errans, constituye efectivamente un medio de tutela, por el que no se inclinó en un principio, pero que admite, porque precisamente le permite satisfacer el interés que perseguía al momento de celebración del contrato y del que el error lo privó. Así lo corrobora, por lo demás, la noción de remedios o medios de tutela en sentido amplio, pues no solo se restringe a las pretensiones y derechos potestativos del acreedor ${ }^{23}$, sino a los cursos de acción de que dispone para enfrentar tal insatisfacción ${ }^{24}$.

Por lo mismo, no resulta tan claro que el errans pueda exigir mantener el contrato con el contenido que él lo entendió, pues los artículos que hemos venido analizando establecen que es el otro contratante quien manifiesta su voluntad de cumplirlo o simplemente lo ejecuta en tales términos, con el propósito de permanecer vinculado a aquel en una versión modificada de la relación contractual original. En otras palabras, si se trata de una propuesta de adaptación, y no de una exigencia, es porque el contrato original no garantizaba el interés de quien incurrió en error, sino uno diverso, que ha debido modificarse como consecuencia de la falsa representación de la realidad en que aquel incurrió.

${ }^{21}$ Morales, A., "Validez del...”, op. cit., p. 393, De la Maza, I., "Libertad y seguridad...", op. cit., Gaspar, S., op. cit., p. 303.

${ }^{22}$ Morales, A., “¿Es posible construir un sistema precontractual de remedios...”. , op. cit., p. 413.

23 Ibid., op. cit., p. 402.

${ }^{24}$ En similar sentido Campbell, D., Introduction: the function and structure of remedies for failure to perform a contractual obligation en Harris, D.; Campbell, D.; Halson, R., Remedies in Contract E Tort, University Press, second edition, Cambridge, 2005, p. 3. 
Más discutida y controvertida ha sido la adaptación del contrato en los supuestos de error compartido. Esta causal solo se encuentra regulada en los artículos 4:105 (2) de los PECL y II.-7:203 (2) del DCFR, adopta una modalidad judicial y tiene lugar si ambas partes incurren en error, y el juez, a petición de cualquiera de ellas, y en la medida que ninguna hubiera impugnado el contrato, adapta su contenido, otorgándole el sentido que razonablemente hubieran acordado si no hubiera existido error. Además, la adaptación podrá pedirla tanto la parte que ha sido perjudicada por el error, pero que aun así quiere mantener el contrato, como aquella que resulta beneficiada con él, con el propósito de impedir la anulación solicitada por la otra. Dicha facultad, como precisa el profesor Morales Moreno, se explica porque la materia en que incide el error es el contenido contrato cuya finalidad es la satisfacción del interés del acreedor ${ }^{25}$.

Tal hipótesis se presenta si el contratista que instalaría el suelo del referido edificio y el contratante se confundieran en cuanto al trabajo que era necesario realizar, caso en el que cada uno de ellos puede solicitar la adaptación judicial del contrato y el tribunal aplicar las tarifas previstas en este para el trabajo adicional, con los ajustes correspondientes al volumen del trabajo afectado. Otro tanto ocurriría si un individuo vende a otro un cuadro por $\$ 80.000$ en la creencia que su autor es poco conocido y se enteran que pertenece a un artista famoso y su valor asciende a $\$ 8.000 .000$, obligándose el comprador a pagar la diferencia ${ }^{26}$.

Esta modalidad de adaptación ha sido criticada por la dificultad que envuelve para el juez arribar a un criterio que permita ajustar equitativamente el contrato. Lo más razonable parece ser extraerlo de la regulación contenida en él, pero existen casos en que ello no será posible. Así, en el evento que la instalación del referido suelo implique más horas de trabajo, el precio del servicio debería incrementarse en la proporción del valor asignado para cada hora de trabajo prevista en el contrato ${ }^{27}$. Distinto es el caso del cuadro que hemos referido, pues no existe un parámetro objetivo en el contrato para determinar su precio, si efectivamente su autoría pertenece a un pintor altamente reconocido. En tal hipótesis, el juez deberá ponderar los valores ofrecidos por ambos contratantes y cotejarlos con el valor de mercado para arribar a una solución justa.

El problema se presenta si, razonablemente, puede entenderse que alguna de las partes no lo habría celebrado de no haber existido error, lo que ocurrirá si la adaptación establece condiciones sustancialmente distintas a las pactadas. Piénsese, en la instalación del suelo, en que el incremento de costo que implica el mayor trabajo requerido o el tiempo que debe emplearse para realizarla distancia el precio de la obra del previsto en términos tales que resulta razonable pensar que el comitente no hubiera pagado ese precio o que el contratista no se hubiera vinculado con aquel. Una hipótesis similar se aprecia

${ }^{25}$ Morales, A., El error..., op. cit., p. 88 y Morales, A., "Validez del...", op. cit., p. 393.

${ }^{26}$ Esos son los ejemplos formulados por los Comentaristas de los PECL (Lando, O.; Beale, H., Principios de derecho..., op. cit., pp. 352-353).

${ }^{27}$ Morales, A., "Validez del...", op. cit., pp. 393 y 394. 
si el comprador de la obra de arte no estuviera en condiciones de pagar $\$ 8.000 .000^{28}$. Se advierte así un segundo límite a la procedencia de la adaptación del contrato, cual es, su conveniencia ${ }^{29}$, que no concurre en las dos situaciones que venimos comentando, de modo que esta debe descartarse, debiendo satisfacerse el interés errans por vía indirecta por medio de la nulidad y la indemnización complementaria, si ellas fueran procedentes.

De lo dicho hasta acá fluye claramente que este medio de tutela precontractual concibe al error como un dispositivo de distribución del riesgo de la información defectuosa durante la negociación del contrato más que como un vicio del consentimiento, pues evita que quien lo padece traspase, sin ninguna justificación, dicho riesgo a quien ha confiado razonablemente en la apariencia creada por aquel. En otras palabras, se desliga de la subjetividad del que ha sufrido el error, desplazándose a la protección de la confianza generada por el contrato y a la seguridad del tráfico jurídico. Este ha sido el enfoque que ha adoptado el movimiento de modernización del derecho de obligaciones y contratos, como lo revelan los artículos 3.2.2 (2) de los PICC, 4:103 (2) de los PECL, II.- 7:201(2) del DCFR, 1298.3 de la PME, 527-5 de la PAPDC y 29 (2) de los PLDC, pues establecen, en términos generales, que el errans debe cargar con dicho riesgo ${ }^{30}$ mediante la mantención del contrato en dos supuestos: a) si ha incurrido en culpa grave al cometer el error, o; b) este versa acerca de una materia respecto de la cual ha asumido el riesgo del error o, tomándose en consideración las circunstancias del caso, debe soportarlo.

$\mathrm{Y}$ es que, como acertadamente ha precisado Morales Moreno ${ }^{31}$, el error produce una alteración en la organización de los intereses del contrato que no solo se traduce en la insatisfacción del interés de uno de los contratantes, sino que, en algunos casos, en una organización de intereses lesiva que rompe la equivalencia que este había establecido para las partes. En palabras de Díez-Picazo ${ }^{32}$, el problema del error radica en determinar en qué casos es justo que el equivocado se desligue o, a pesar de la equivocación, continúe

${ }^{28}$ Supuestos similares exponen Lando, O.; Beale, H., Principios de derecho..., op. cit., pp. $352-353$ y Morales, A., "Validez del...", op. cit., pp. 392 y 394

${ }^{29}$ Lando, O.; Beale, H., Principios de derecho..., op. cit., pp. 352-353, Morales, A., "Validez del...", op. cit., p. 394, De la Maza, I., "Libertad y seguridad...”, op. cit., p. 513 y Gaspar, S., op. cit., p. 303.

${ }^{30}$ Un completo análisis en Neme, M. L., "El error como vicio del "consentimiento" frente a la protección de la confianza en la celebración del contrato, Revista de Derecho Privado Universidad Externado de Colombia, $\mathrm{N}^{\circ} 22$, enero-junio, 2012, pp. 169-218 y a propósito del Borrador de los PLDC en De la Maza, I., "El error en los Principios Latinoamericanos de Derecho de los Contratos”, en Vaquer, A.; Bosch, E.; Sánchez, M. P. (edits.), El derecho común europeo de la compraventa y la modernización del derecho de contratos, Editorial Atelier, Barcelona, 2015, pp. 789-799.

${ }^{31}$ Esta idea planteada inicialmente por Morales, A., El error..., op. cit., pp. 79-80, 88-90 y 99-105, ha sido recepcionado en la doctrina nacional por De la Maza, I., "El error vicio del consentimiento: Entre la protección y el aprovechamiento", en Elorriaga, F. (coord.), Estudios de Derecho Civil VII, Editorial AbeledoPerrot LegalPublishing, Santiago, 2012, pp. 511-523 y De la Maza, I., "El error en los Principios Latinoamericanos...", op. cit., pp. 789-799.

32 Díez-Picazo, L., Fundamentos del Derecho Civil Patrimonial I. Introducción Teoría del Contrato, 6a ed., Editorial Civitas, Madrid, 2007, pp. 208-209. 
estándolo. De ahí que se sugiera abordarlo desde una perspectiva funcional, esto es, como un problema de justa o conveniente distribución del riesgo entre los contratantes. ${ }^{33}$

Pues bien, un examen preliminar de la regulación del error en nuestro Código Civil podría inclinarnos a pensar que este medio de tutela no tiene cabida a propósito del error vicio, pues el legislador solo faculta a quien lo experimenta a impetrar la nulidad del contrato y ni siquiera se pronuncia respecto de la posibilidad que este sea compartido por el declarante y su destinatario. Pero como sugeriremos cuando abordemos este tópico en el próximo apartado, es posible intentar una relectura de las disposiciones que lo regulan, junto con otras más generales, que permitirán concebirlo como un supuesto de adaptación del contrato y perfilarlo como un medio de tutela precontractual en nuestro ordenamiento jurídico.

\section{El provecho excesivo, ventaja desleal, explotación injusta, excesiva desproporción o ventajismo}

El segundo supuesto en que resulta procedente la adaptación del contrato, al igual que el anterior, constituye, en la mayoría de los Código Civiles y en los instrumentos contractuales de soft law, un vicio del consentimiento que se configura en aquellos casos que una de las partes se aprovecha injustificadamente de la dependencia, aflicción económica, necesidades apremiantes, falta de previsión o habilidad en la negociación, ignorancia o inexperiencia de la otra y que ha venido en denominarse provecho excesivo, ventaja desleal, explotación injusta o excesiva desproporción ${ }^{34}$.

Como se advierte, dicha noción equivale a lo que algunos Códigos decimonónicos denominaron lesión enorme, acuñando un criterio objetivo-subjetivo o mixto, según el cual, ella existirá en aquellos casos en que se verifique una asimetría prestacional en la proporción establecida por la ley y esta encuentre su origen en inexperiencia, ligereza, debilidad o estado de necesidad, aflicción económica o falta de habilidad en la negociación de quien resulta perjudicado por tal desequilibrio. Tal es el caso del parágrafo 138.2 del BGB y los artículos 21 del Código suizo de 1912, 17 del Código mexicano de 1928, 1447 y 1448 del Codice de 1942, 282 del Código Civil portugués de 1966, 1447 del Código Civil peruano de 1985, 157 del Código brasilero de 2002, 332 del Código Civil y Comercial argentino y $1118 \mathrm{del}$ Code, recientemente modificado por el artículo 1168 de la Ordenanza N $2016-131$ de 10 de febrero de $2016^{35}$.

${ }^{33}$ Morales, A., El error..., op. cit., pp. 89 y 90.

${ }^{34}$ Un completo análisis de esta institución en el soft law en Ginés Castellet, N., "La ventaja o explotación injusta en el ¿futuro? Derecho contractual”, Indret Privado 4, 2016, octubre, en http://www.indret.com/ pdf/1264_es.pdf (consultada el 5 de enero de 2017).

${ }^{35}$ El antiguo artículo 1118 señalaba que "la lesión no vicia las convenciones sino en ciertos contratos y respecto de ciertas personas, tal como se explicará en las secciones respectivas”, técnica que mantiene el nuevo, pues señala que "en los contratos bilaterales la falta de equivalencia de las prestaciones no es una causa de nulidad, a menos que la ley disponga lo contrario". Para un comentario de esta modificación véase Chantepie, G.;Latina, M., La réforme du droit des obligations. Commentaire théorique et practique dans l'ordre du 
La conveniencia de acuñar el criterio mixto radica en superar las falencias del objetivo y los inconvenientes derivados del subjetivo. Y es que, puede ocurrir que, no obstante existir una desproporción matemática, el contrato sea injusto y que, a pesar de la inferioridad de una de las partes, la asimetría prestacional no pueda medirse, porque no existe una fórmula destinada a tal efecto. Con todo, la desventaja es que, salvo el caso del Código Civil Peruano de 1985 y el Codice de $1942^{36}$, las regulaciones que acuñan una noción mixta no fijan un criterio matemático que permita calibrar objetivamente el desequilibrio, sino que emplean fórmulas genéricas como "en desproporción evidente respecto a dicha prestación"( $\$ 138.2$ del BGB de 2002), "desproporción evidente entre la prestación prometida por una de las partes y la contraprestación de la otra” (art. 21 Código Suizo), lucro excesivo que sea evidentemente desproporcionado (art. 17 Código mexicano), beneficios excesivos o injustificados (art. 282 del Código Civil portugués de 1966), prestación manifiestamente desproporcionada en comparación a su contraprestación (art. 157 del Código brasilero de 2002), ventaja patrimonial evidentemente desproporcionada y sin justificación (art. 332 del Código Civil y Comercial argentino) y "falta de equivalencia de las prestaciones" (art. $1168 \mathrm{del}$ Code).

Por consiguiente, exigen la intervención del juez ${ }^{37}$, quien debe actuar prudentemente y procurar resguardar los intereses de los contratantes, evitando cualquier arbitrariedad en tal ponderación. A ello se agrega que, como se trata de un criterio restrictivo, pues, para que se configure, el legislador debe contemplar la lesión enorme, expresamente, como un vicio del consentimiento, sin que pueda inferirse su intención en tal sentido, la prueba es más compleja, resultando conveniente establecer una presunción simplemente legal de aprovechamiento o explotación injusta. En tal sentido destaca, entre otros ${ }^{38}$, el artículo 1448 del Código Civil Peruano de 1984 que establece que si la desproporción fuera igual o superior a las dos terceras partes, se presume el aprovechamiento por el lesionante de la necesidad apremiante del lesionado ${ }^{39}$. Similar técnica legislativa sigue el artículo 671 del Código Civil de Paraguay, ya que prescribe que "la notable desproporción entre las

Code Civil, Dalloz, Paris, 2016, pp. 350-354 y Deshayes, O.; Genicon, T.; Laithier, Y. M., Reforme du droit des contracts, du régimen générale et de la prevue des obligations. Comentaire article par article, Lexis Nexis, 2016.

${ }^{36}$ El primero indica que la rescisión por lesión solo puede ejercitarse cuando la desproporción entre las prestaciones al momento de celebrarse el contrato es mayor de las dos quintas partes y siempre que tal desproporción resulte del aprovechamiento por uno de los contratantes de la necesidad apremiante del otro, agregando los contratos aleatorios, cuando se produzca la desproporción por causas extrañas al riesgo propio de ellos. Por su parte, el segundo señala que "la acción es admisible si la lesión excede de la mitad del valor que la prestación, ejecutada o prometida por la parte damnificada, tenía al tiempo del contrato (...)”.

37 Sobre tal intervención véase Momberg, R., "La reformulación del rol del juez en los instrumentos contemporáneos de derecho contractual", Revista de Derecho Universidad Católica del Norte, año 21, $\mathrm{N}^{\circ} 2$, 2014, pp. 277-304.

${ }^{38}$ Un análisis de este tópico en Carranza, C., La presunción de aprovechamiento en la lesión contractual, Tesis de Magíster Pontificia Universidad Católica del Perú, 2012, pp. 50-59, disponible en http://tesis.pucp.edu.pe/ repositorio/bitstream/handle/123456789/4599/CARRANZA_ALVAREZ_CESAR_LESION_CONTRACTUAL. pdf? sequence $=1$, consultado el 5 de noviembre de 2016 .

${ }^{39}$ Sobre el alcance de esta presunción y las discusiones a que ha dado lugar Carranza, C., La presunción de aprovechamiento..., op. cit., pp. 60-90. 
prestaciones hace presumir la explotación, salvo prueba en contrario”. Esta fórmula ha sido recogida recientemente por el inciso segundo del artículo 332 del Código Civil y Comercial argentino que, al igual que aquel, siguió el tenor literal del inciso segundo del antiguo artículo 954 del Código Civil argentino ${ }^{40}$.

Este criterio objetivo-subjetivo también ha sido acuñado por el soft law bajo diversas denominaciones que pretenden graficar el mismo fenómeno, pero no contemplan la presunción que venimos comentando. Así lo evidencian los artículos 3.2.7 de PICC, 4:109 de los PECL y II.- 7:207 del DCFR e incluso el artículo 37 del PLDC que, siguiendo el modelo de los PICC, exigen atender además a la naturaleza y finalidad del contrato. Semejante idea se recoge en el ordenamiento jurídico español, pues actualmente se encuentra a la espera de la aprobación de la Propuesta de modificación que introduce la noción de ventaja excesiva (art. 1301 de la PME) o ventajismo (art. 527-9 de PAPDC).

En efecto, el artículo 3.2.7 de los PICC regula la excesiva desproporción en los siguientes términos: "(1) Una parte puede anular el contrato o cualquiera de sus cláusulas si en el momento de su celebración el contrato o alguna de sus cláusulas otorgan a la otra parte una ventaja excesiva. A tal efecto, se deben tener en cuenta, entre otros, los siguientes factores: (a) que la otra parte se haya aprovechado injustificadamente de la dependencia, aflicción económica o necesidades apremiantes de la otra parte, o de su falta de previsión, ignorancia, inexperiencia o falta de habilidad en la negociación; y (b) la naturaleza y finalidad del contrato". Esta fórmula es recogida en términos muy similares por el artículo 37 de los PLDC que, refiriéndose a la excesiva desproporción, señala: "(1) Una parte puede demandar la adaptación del contrato o de cualquiera de sus cláusulas, o su nulidad si otorgan a la otra una ventaja excesiva contraria a las exigencias de la buena fe. (2). Para calificar esa ventaja se deben tomar en cuenta todas las circunstancias, especialmente la dependencia de la parte que sufre el perjuicio, las extraordinarias dificultades económicas que la aquejan, la apremiante urgencia de sus necesidades, su ignorancia o falta de experiencia. Igualmente, deberá considerarse la relación de confianza existente entre las partes y la naturaleza y finalidad del contrato".

Por otra parte, el artículo 4:109 de los PECL relativo al Beneficio o ventaja injusta, que es reproducido literalmente por el artículo II.- 7: 207 del DCFR, prescribe lo siguiente: “(1) Una parte puede anular el contrato si, en el momento de su conclusión: (a) dependía de la otra parte, tenía una relación de confianza con ella, se encontraba en dificultades económicas o tenía otras necesidades urgentes, no tenía capacidad de previsión o era ignorante, inexperimentado o carente de capacidad negociadora, y (b) la otra parte conocía o debería haber conocido dicha situación y, atendidas las circunstancias y el objeto del contrato, se aprovechó de ello de manera claramente injusta u obtuvo así un beneficio excesivo".

Finalmente, destaca la regulación de las Propuestas españolas, pues el artículo 1301 de la PME refiriéndose a la ventaja excesiva dispone: "Una de las partes puede anular el contrato que, en el momento de su celebración, otorga a la otra parte una ventaja

${ }^{40}$ En lo que concierne a la extensión de la presunción contenida en el referido artículo 954, análisis que resulta plenamente aplicable a aquellas, véase Martín, J.A., La rescisión del contrato: en torno a la lesión contractual y el fraude de los acreedores, Editorial Bosh, Barcelona, pp. 98-102. 
excesiva si, teniendo en cuenta la naturaleza y fin de aquel, resulta que se ha aprovechado injustamente de una situación de dependencia, de extraordinarias dificultades económicas o de necesidad apremiante, o de su ignorancia, de su inexperiencia o falta de previsión. A petición de la parte perjudicada, puede el juez introducir en el contrato aquellas modificaciones que sean necesarias para adaptarlo a las exigencias de la buena fe y lo que sea usual en el tráfico jurídico". Este modelo es seguido muy de cerca por el artículo 527-9 de la PAPDC, que bajo el epígrafe Ventajismo señala que: “1. Una de las partes puede anular el contrato que en el momento de su celebración otorga a la otra parte una ventaja excesiva, si, teniendo en cuenta la naturaleza y fin de aquel, resulta que, con conocimiento de causa, se ha aprovechado en contra de la buena fe de una situación de dependencia, de extraordinarias dificultades económicas o de necesidad apremiante, o de su ignorancia, de su inexperiencia o falta de previsión. 2. También puede la parte perjudicada pretender el reequilibrio del contrato sobre la base del precio generalmente practicado en el mercado".

Pues bien, una sistematización de estas regulaciones revela que existen dos modelos tanto para configurar la excesiva desproporción o ventaja injusta como para determinar el monto en que debe reducirse la prestación excesiva para adaptar el contrato. En efecto, en lo que concierne a su determinación, si bien se exige la concurrencia de un doble elemento subjetivo, representado por el aprovechamiento o explotación injustificada y la situación de debilidad de la víctima ${ }^{41}$, es posible advertir un modelo base que acuñan los PECL, el DCFR y la PME y otro que le agrega a aquella como factores adicionales "la naturaleza y finalidad del contrato”, recogida por los PICC, los PLDC y la PAPDC. La incorporación de estos criterios para ponderar la existencia de la excesiva desproporción encuentra su justificación en el hecho que existen situaciones en que la ventaja excesiva es injusta, aun cuando el beneficiario no haya abusado de la posición negociadora más débil de la otra parte. Así, por ejemplo, la comisión cobrada por un agente comercial, establecida en razón de un porcentaje del precio de las mercaderías vendidas o servicios prestados, podría justificarse por su contribución sustancial para celebrar esas operaciones o porque el valor de las mercaderías o servicios no es muy alto, pero podría significar una ventaja excesiva para dicho agente si su participación en esas operaciones ha sido insignificante o si el valor de aquellos llega a ser extremadamente elevado ${ }^{42}$.

${ }^{41}$ Esta situación comprende la dependencia, las extraordinarias dificultades económicas, la necesidad apremiante o aflicción económica, la ignorancia, inexperiencia y falta de habilidad en la negociación. Para un análisis véase, entre otros, Carranza, C., "Apuntes sobre la excesiva desproporción prestacional en el contrato. Una mirada a los Principios del UNIDROIT", Revista Colombiana de Derecho Internacional Pontificia Universidad Javeriana, N 4, 2004, pp. 388-393, Martín, J.A., op. cit., pp. 93-97 y Bosch, E., "La anulación del contrato por explotación injusta en la Propuesta de Anteproyecto de Ley de Modernización del Derecho de Obligaciones y Contratos", en Bosch, E. (dir.), Nuevas perspectivas del derecho contractual, Editorial Bosh, Barcelona, 2012, pp. 376-383).

42 UNIDROIT, Instituto Internacional para la Unificación del Derecho Privado, en Garro, A. (dir.), Rodríguez, J.M; Perales, p. (cols.), Principios UNIDROIT sobre los contratos comerciales internacionales, Ediciones UNIDROIT, Madrid, 2010, p. 118. 
Tratándose de la cuantía en que debe adaptarse el contrato, los preceptos que hemos venido comentando introducen diversos parámetros que el juez deberá tener en consideración para efectuar el ajuste de las prestaciones, exigiendo, por un lado, atenerse a factores económicos o a la buena fe, y, de otro, considerar ambos elementos. En efecto, aluden a "criterios comerciales razonables de lealtad negocial" (art. 3.2.7 (2) de los PICC), a la "base del precio generalmente practicado en el mercado (art. 527-9 de la PAPDC), a "lo que podría haberse acordado respetando el principio de la buena fe contractual" (art. 4.109 (2) de los PECL, II.- 7: 207 (2) del DCFR y art. 37 (3) de los PLDC) y a las “exigencias de la buena fe y lo que sea usual en el tráfico jurídico" (art. 1301 de la PME). De otro lado, suponen una acuciosa labor de los litigantes en orden a demostrar al juez el precio generalmente aceptado en el mercado, los criterios comerciales razonables y el alcance de la función integradora de la buena fe negocial en el caso concreto.

Lo cierto es que, a pesar de la generalidad y amplitud con que se regula la explotación injusta o excesiva desproporción en el soft law, el mérito que debe reconocérsele es que añade una ventaja adicional a aquella derivada del criterio objetivo-subjetivo de lesión enorme, toda vez que faculta al contratante perjudicado para optar entre impetrar la nulidad del contrato o solicitar su adaptación, evitando así la aniquilación de este. En efecto, salvo el caso de los artículos 1301 de la PME y 527-9 de la PAPDC, los diversos artículos que hemos venido revisando precisan que tal adaptación no solo la puede solicitar la parte legitimada para alegar la nulidad, sino aquella que recibió la notificación de anulación, siempre que lo comunique inmediatamente a la otra parte y esta última no haya actuado razonablemente en razón de dicha notificación. En tal caso, la parte legitimada para impetrar la nulidad pierde este derecho y cualquier notificación en tal sentido, realizada con anterioridad, quedará sin efecto, deviniendo así la adaptación del contrato en un límite a la nulidad.

Claro está que nuestro Código Civil no recoge un criterio subjetivo de lesión enorme que permita concebirla como un vicio del consentimiento, pues así se desprende del artículo 1451 que no la menciona como tal y de la asimetría aritmética o matemática que exige para que esta se configure en los supuestos que la regula ${ }^{43}$. Pero por esa circunstancia no significa que la lesión enorme no constituya un supuesto de adaptación del contrato, pues como intentaremos demostrar en el apartado siguiente ella es en realidad una manifestación del equilibrio originario orientada prevalentemente a esta finalidad. Este criterio solo permite descartar que ella acarree la rescisión del acto o contrato, fuera de los supuestos expresamente regulados por nuestro legislador, toda vez que dicha sanción de ineficacia es de derecho estricto, de modo que no puede aplicarse por analogía.

43 Este criterio objetivo excepcionalmente lo mantienen el Código Civil chileno, el colombiano, ecuatoriano, en los mismos supuestos y bajo la misma fórmula que el nuestro, y el español, tratándose de los contratos que pudieren celebrar los tutores en favor de los menores e incapacitados, aquellos otorgados en representación de los ausentes sin autorización judicial, cuando estos o aquellos hayan sufrido lesión en más de la cuarta parte del valor de las cosas que hubiesen sido objeto de los contratos celebrados y en cualquier otro supuesto que determine la ley (art. $1291 \mathrm{~N}^{\circ} 1,2$, y 5.) 


\section{Modalidades de la adaptación del contrato en el Código Civil CHILENO COMO MEDIO DE TUTELA PRECONTRACTUAL}

Como es ampliamente sabido, nuestro Código Civil, al igual que la mayoría de los Códigos decimonónicos, con excepción del Codice, los Códigos Civiles de Portugal, Bolivia, Paraguay, el Código Civil y Comercial argentino y, recientemente, el Code ${ }^{44}$, no prestó especial atención a la fase precontractual, desplazando la regulación de la formación del consentimiento a los artículos 97 al 105 del Código de Comercio, circunscribiéndose tan solo a los vicios de la voluntad, la lesión enorme y la nulidad y los efectos derivados de ella.

Esta escueta regulación ha determinado la necesidad de explorar dogmáticamente dicha fase, focalizándose la atención en la responsabilidad que puede surgir como consecuencia de la infracción de los deberes precontractuales de lealtad, información, conservación y custodia ${ }^{45}$ y en la necesidad de concebir al error como un dispositivo de distribución de riesgos de la información defectuosa, abordándolo ya no desde la perspectiva del consentimiento viciado, sino en razón de si resulta justo que el errans quede vinculado contractualmente y continúe estándolo ${ }^{46}$.

En tal escenario y, a falta de un pronunciamiento dogmático respecto de la procedencia de la adaptación del contrato, es posible indagar si nuestro Código contempla alguna hipótesis en que esta sea procedente, distinta o similar a aquellas tipificadas actualmente en el soft law o en los Códigos Civiles que hemos examinado, que permita incardinarlo en el sistema de tutela precontractual ${ }^{47}$, promoviendo la conservación del contrato. A tal efecto abordaremos, primeramente, un caso expresamente previsto en él, cual es, la lesión enorme y, seguidamente, un supuesto inexplorado, representado por el error vicio unilateral o compartido.

1. Un supuesto regulado en el Código Civil: la lesión enorme como manifestación del equilibrio contractual originario orientada prevalentemente a configurar la adaptación del contrato

Una lectura preliminar de las disposiciones que regulan la lesión enorme en nuestro Código nos podrían llevar a sostener que solo existen tres casos en que ella permite al contratante perjudicado solicitar la rebaja de la prestación excesiva, instando así por la

${ }^{44}$ En efecto, el artículo 1337 del Codice indica que las partes en el desarrollo de las negociaciones y en la formación del contrato deben comportarse de acuerdo a la buena fe, consagrando la misma regla, respectivamente, los artículos 465, 689 y 991 de los Códigos Civiles de Bolivia, Paraguay y el Código Civil y Comercial argentino. Por su parte, el artículo 227 del Código Civil portugués, agrega la responsabilidad por los daños que culposamente cause a la otra parte. Finalmente, el Code, en sus artículos 1112 a 1187 regulan la oferta y la aceptación, los deberes precontractuales y los contratos preparatorios.

45 Véase los autores indicados en la nota 5.

46 De la Maza, I., “El error vicio del consentimiento...”, op. cit., pp. 511-523.

${ }^{47}$ López, P.V., "Por la articulación de un sistema...”., op. cit. 
adaptación del contrato. Estas son la cláusula penal enorme (art. 1544), el mutuo con intereses excesivos (arts. 2208) y la anticresis (art. 2443). De hecho, así se ha sostenido tradicionalmente, abogándose, solo en el último tiempo, por la idea según la cual, tratándose de la cláusula penal, la reducción de la prestación no es, por consiguiente, un supuesto de lesión enorme, sino una consecuencia propia de aquella, constituyendo mecanismos de control diversos. ${ }^{48}$

Sin embargo, una lectura más detenida revela que independientemente que acojamos una noción amplia, esto es, que se proyecte más allá de los siete casos regulados por el legislador y cuyo efecto sea la rebaja de la prestación excesiva ${ }^{49}$, examinando solo dichas hipótesis, es posible advertir que la lesión enorme constituye una manifestación del equilibrio contractual originario orientada prevalentemente a alcanzar la adaptación del contrato, ya que, como tendremos ocasión de examinar, tal efecto puede extenderse a dos supuestos indiscutidos en que ella tiene lugar: la compraventa de bienes inmuebles y la permuta de estos.

De hecho, en la doctrina comparada se ha sostenido que este debiera ser el efecto general de la lesión enorme, cuya conveniencia es evidente, toda vez que no solo elimina el daño, restableciendo la simetría de las prestaciones sino que, además, permite mantener el contrato ${ }^{50}$. Recogiendo esta idea, el artículo 1452 del Código Civil peruano establece un orden de prelación entre la rescisión y la rebaja de la prestación, pues indica que si la acción rescisoria fuera inútil para el lesionado, por no ser posible que el demandado devuelva la prestación recibida, procederá la acción de reajuste ${ }^{51}$. Otro tanto acontece con el artículo 1294 del Código Civil español, pues prescribe que la acción de rescisión es subsidiaria, precisando que no podrá ejercerse sino cuando el perjudicado carezca de otro recurso legal para obtener la reparación del perjuicio. Distinto es el mecanismo contemplado en el inciso cuarto del artículo 332 del nuevo Código Civil y Comercial argentino, porque regula la opción entre ambos, pero advierte que la nulidad se transformará en acción de reajuste si este fuere ofrecido por el demandado al contestar la demanda. Finalmente, existe un tercer sistema que consiste en otorgar al contratante lesionado una libre opción entre la nulidad del contrato y su adaptación o modificación equitativa, inicialmente recogido

${ }^{48}$ En efecto, Corral las diferencia, atendiendo a la causa y momento en que tiene lugar la desproporción y los efectos que estas acarrean (Corral H., Contratos y daños por incumplimiento, Editorial AbeledoPerrot Legalpublishing, Santiago, 2010, pp. 308-309).

${ }^{49}$ En tal sentido López P.V., "Por una noción amplia de Lesión Enorme en el Código Civil chileno: una relectura a partir del principio de equilibrio contractual y la idea de excesiva desproporción contenida en el Borrador de los Principios Latinoamericanos de derecho de los contratos”, en Vidal, A.; Severin, G.; Mejías, C., Estudios de Derecho Civil X, Editorial Thomson Reuters, La Ley, Santiago, 2015, pp. 699-723.

${ }^{50}$ En una dirección similar se han pronunciado Moisset, L., La lesión en los actos jurídicos, Dirección General de Publicaciones de la Universidad Nacional de Córdoba, Córdoba, 1979, p. 248 y Carranza, C., La presunción de aprovechamiento..., op. cit., p. 43.

${ }^{51}$ Con todo, la doctrina peruana se encuentra dividida en torno al alcance de dicho precepto, pues hay quienes postulan que efectivamente la acción de reajuste es subsidiaria y excepcional y otros que sugieren que el contratante lesionado puede optar entre la rescisión y el reajuste. Un acabada exposición de este tópico en Carranza, C., La presunción de aprovechamiento..., op. cit., pp. 41-45. 
por los artículos 17 del Código Civil mexicano ${ }^{52}$ y 671 del Código Civil de Paraguay 53 y que, actualmente, se aprecia en el artículo 157 del Código Civil de Brasil ${ }^{54}$ y en los artículos 1301 de la PME, 527-9 de la PAPDC y 37 de los PLDC, ya examinados.

Pues bien, a falta de una norma general que establezca el efecto de la lesión enorme en nuestro Código Civil y, atendido que la rescisión es una sanción de ineficacia de derecho estricto, es factible preguntar si este podría ser la adaptación del acto o contrato. Como adelantamos, un recuento preliminar arrojaría que los casos en que tiene lugar la rebaja de la prestación o adaptación del contrato son la cláusula penal enorme, el mutuo con intereses excesivos y la anticresis, pero si se adicionan los casos de opción en favor de la rebaja o adecuación de la prestación en la compraventa (artículo 1890) y permuta de bienes inmuebles (artículo 1900), estos aumentarían a cinco. De hecho, una revisión más acuciosa incluso revela el mismo fenómeno en la partición de bienes, aun cuando se discuta si, efectivamente, constituye un caso de lesión enorme ${ }^{55}$, pues el artículo 1350 indica que podrán los otros partícipes atajar la acción rescisoria de uno de ellos, ofreciéndole y asegurándole el suplemento de su porción en numerario.

Restaría tan solo la aceptación de una asignación hereditaria, supuesto en el cual el artículo 1234 contempla la rescisión por lesión enorme y que, al igual que el anterior, ha sido criticado por alguna doctrina, precisando que ella no tendría lugar, porque no se advertiría una falta de equivalencia prestacional ${ }^{56}$. De allí que pueda sostenerse que, en todas las hipótesis que el legislador contempla expresamente la lesión enorme (si admitimos que en esta se configura en la cláusula penal enorme, la aceptación de una asignación hereditaria y la partición de bienes) o en la mayoría de

52 Este precepto indica, en su parte pertinente que "el perjudicado tiene derecho a elegir entre pedir la nulidad del contrato o la reducción equitativa de su obligación, más el pago de los correspondientes daños y perjuicios".

53 El referido artículo 671, en lo que aquí interesa, prescribe lo siguiente: "Si uno de los contratantes obtiene un ventaja manifiestamente injustificada, desproporcionada con la que recibe el otro, explotando la necesidad, la ligereza o la inexperiencia de éste, podrá el lesionado, dentro de dos años demandar la nulidad del contrato o su modificación equitativa".

${ }^{54}$ Dicho artículo establece en su numeral dos que "no se decretará la anulación del negocio, si se ofreciera un suplemento suficiente o si la parte favorecida acordara una reducción del provecho".

55 En efecto, se ha sostenido que tratándose de la partición de bienes el legislador permite solicitar su rescisión si se verifica la desproporción del artículo 1348, ya que se infringe el principio de igualdad de los berederos que informa la partición, de modo que deviene en una especial sanción de tal infracción (Peñailillo, D., "La revisión judicial de obligaciones y contratos en la reforma del Código Civil (La lesión y la imprevisión)", en Revista de Derecho Universidad de Concepción, año 68, N 208, 2000, p. 216).

${ }^{56} \mathrm{La}$ justificación de su procedencia en la asignación hereditaria se ha fundado en la equidad, pues se ha indicado que como existiría una menor ventaja patrimonial o un perjuicio derivado de la ignorancia o error que no es imputable a quien acepta dicha asignación, el legislador, por una razón de justicia, le permitiría rescindir tal aceptación (Domínguez, R.; Domínguez, R., Derecho Sucesorio. $3^{\text {a }}$ ed. actualizada, Editorial Jurídica de Chile, Santiago, 2011, p. 227, quienes indican que difícilmente un asignatario sostendrá la nulidad de su aceptación por recibir gratuitamente menos de lo que esperaba, motivo por el cual es difícil justificar la existencia de este supuesto). A propósito del perjuicio derivado de la ignorancia o error véase Peñailillo, D., op. cit., p. 216 y Alessandri, A.; Somarriva, M.; Vodanovic, A., Tratado de derecho civil: parte preliminar y parte general. Tomo II. $7^{\mathrm{a}}$ ed., Editorial Jurídica de Chile, Santiago, 2005, p. 245. 
ellas (si consideramos que en tales casos no existe lesión), el efecto prevalente derivado de ella es la adaptación del acto o la renegociación del contrato en la modalidad rebaja de la prestación excesiva orientada a la conservación de la relación contractual, en la cuantía que el legislador indica en cada caso.

Pero nuestra constatación puede adquirir un efecto expansivo si adherimos a una noción amplia de lesión enorme que ha encontrado sustento en la intención que tuvo el legislador de ampliar su ámbito de aplicación al eliminar el artículo 1639 del Proyecto de 1853, la ausencia de norma que restringa su procedencia a determinados supuestos o que la prohíba en términos generales, el principio de equilibrio contractual que consagra nuestro Código $\mathrm{Civil}^{57}$ y la necesidad de armonizar el alcance de la lesión enorme contenida en él con la excesiva desproporción de los PLDC ${ }^{58}$. Tal noción adquiere relevancia en aquellos supuestos en que el legislador no contemple ningún mecanismo de tutela respecto de un contratante débil que, experimentando una asimetría prestacional cuya causa se encuentra en la fase anterior a la ejecución del contrato, se conforme con mantenerlo por medio de la rebaja de la prestación excesiva.

En el caso que admitiéramos una noción amplia de lesión enorme, ¿cuándo procedería y cuál sería el monto hasta el que podría renegociarse el contrato o, si se quiere, rebajarse la prestación excesiva? A nuestro juicio, la respuesta deriva de la interpretación armónica de los artículos 1544, 2206 y 2443 del Código Civil que se refieren, respectivamente, a la cláusula penal enorme, mutuo con interés excesivos y a la anticresis y que contemplan la rebaja de la prestación excesiva, cuando el desequilibrio supere el cincuenta por ciento del valor de la prestación convenida o del interés correspondiente. Este sería el requisito de procedencia de la adaptación o renegociación y el monto de esta, como también puede desprenderse de esos artículos, equivale a todo aquello que exceda de dicho porcentaje. Tal cuantía, como se verá, puede ser determinante en aquellos supuestos en que esta converja con la rebaja del precio.

De lo dicho hasta acá fluye que, sea que adhiramos a una interpretación estricta de los artículos 1544, 2206 y 2443 del Código Civil y sostengamos que solo en esos casos procede la rebaja de la prestación excesiva, postulemos que tal efecto debe ampliarse a los supuestos en que tiene lugar la rescisión de conformidad a los artículos 1890, 1900 y 1351 o aboguemos por una noción amplia de lesión enorme que acarree tal reducción, esta constituye un supuesto en que el legislador regula la adaptación como medio de tutela precontractual, aunque no utilice tal nomenclatura. De hecho, al igual que en los instrumentos de soft law que hemos venido refiriendo, se advierte una modalidad judicial, en aquellos casos que se reclama mediante la acción de lesión enorme, y una modalidad extrajudicial, que tiene lugar cuando las partes realizan el ajuste prestacional de común acuerdo. Cuestión distinta es que su ámbito de aplicación sea más reducido que aquel otorgado a la excesiva desproporción por dichas regulaciones.

\footnotetext{
${ }^{57}$ López, P.V., "El principio de equilibrio contractual..., op. cit., pp. 115-181.

${ }^{58}$ López, P.V., "Por una noción amplia de Lesión Enorme...”, op. cit., pp. 708-723.
} 


\section{Un supuesto inexplorado: el error vicio unilateral y compartido}

Como lo sostuvimos al examinar la adaptación del contrato en el soft law, este medio de tutela procede en los casos de error vicio unilateral en que, teniendo una de las partes la facultad de impugnarlo, la otra manifieste su disposición a cumplir o cumpliera el contrato tal cual había sido entendido por aquella, y en el supuesto de error vicio compartido en que se le otorgará el sentido que razonablemente habrían acordado las partes de no haber existido error. Ambas hipótesis parecen extrañas a nuestro Código, pues el único efecto, al menos expresamente regulado del error vicio, es la procedencia de la nulidad relativa que acarrea la aniquilación del contrato.

Es posible preguntar entonces, si atendida la conveniencia que en la mayoría de los casos reporta la adaptación del contrato, es posible intentar un relectura de los artículos 1454 y 1455 que regulan el error sustancial y, más restringidamente, el error accidental y el error en la persona, junto con otras normas contenidas en nuestro Código, que permita sostener la procedencia de la adaptación del contrato en supuestos de error vicio unilateral y compartido. La ausencia de norma que contemple la adaptación del contrato como medio de tutela precontractual no debe inclinarnos a excluir inmediatamente esta posibilidad, porque la nulidad por error es una vía indirecta para obtener la satisfacción del interés del contratante que lo padece, pues, quien la solicita, evidencia la inadecuación del contrato para obtener tal satisfacción, procurando alcanzarla mediante su aniquilación. De ahí que Morales Moreno, refiriéndose a este tópico en el derecho español, sostenga que no parece razonable que aquel contratante cuyo interés resulta insatisfecho como consecuencia del error, rechace una posible propuesta del otro contratante destinada a satisfacer directamente su interés por medio de la adaptación del contrato, aunque el contrato no lo imponga y que, tal negativa, constituya un acto contrario a la buena $\mathrm{fe}^{59}$.

Pues bien, siguiendo este razonamiento, debemos resolver si la adaptación del contrato por error unilateral tiene cabida en nuestro Código Civil. Dicho de otra manera, ¿puede la parte que no ha sufrido error ofrecer la rectificación del contrato para impedir el ejercicio de la acción de nulidad por el legitimado? Claro está que no existe ningún artículo en el Código que así lo prevea, pero la omisión del legislador no es un argumento concluyente para erradicar su procedencia, ya que, a nuestro juicio, es posible recurrir a argumentos dogmáticos, así como la medida del interés del errans y los principios de buena fe y renunciabilidad de los derechos, que encuentran sustento normativo en diversas disposiciones contenidas en él.

Y es que una reflexión más detenida revela que el interés del contratante que padeció el error puede calibrarse objetivamente de acuerdo con la regla contractual, pues ella refleja claramente que su propósito fue, en los ejemplos que hemos venido revisando, contratar la instalación del suelo en el tiempo y por el precio pactado o adquirir la obra de arte en el precio convenido. Por consiguiente, tal medida estaría contenida en el

${ }^{59}$ Morales, A., El error..., op. cit., pp. 87-88. 
contrato y lo facultaría, en principio, para optar entre aceptar la adaptación del contrato propuesta por el otro contratante, si se ajusta perfectamente a tal interés, o rechazarla. En el evento que acepte el ofrecimiento del otro contratante alcanzará la satisfacción directa del interés que tuvo al momento de contratar, como si nunca hubiera incurrido en error, perdiendo, por lo mismo, la legitimación para solicitar la nulidad, toda vez que la alteración de los intereses causada por el error ha desaparecido. En cambio, si rechaza tal ofrecimiento, obtendrá la satisfacción indirecta de su interés por medio de la nulidad, lo que resulta ilógico e justificado, si la adaptación aún es posible y conveniente para él, ya que ella le permite alcanzarla directamente, tornándose incluso tal decisión inequitativa para el otro contratante, si este, como en los ejemplos que hemos revisado, ni siquiera ha provocado el error.

Es precisamente en este escenario en el que aparece la buena fe como argumento para sostener la procedencia de la adaptación en el error unilateral, toda vez que el rechazo o negativa del errans sería contrario a ella, pues evidenciaría una conducta que pugnaría con la corrección que deben observar los contratantes en la fase precontractual y sería contradictoria con el mismo interés que lo llevó a contratar. De hecho, tal negativa solo se explicaría si tuviera por propósito perturbar al otro contratante, deviniendo así en un abuso del derecho a demandar la nulidad del contrato ${ }^{60}$. Este argumento permitiría paralizar el ejercicio de la acción de nulidad, lo que no implica que pierda el derecho a satisfacer tal interés por otro medio de tutela ${ }^{61}$, instando, por ejemplo, por la adaptación del contrato.

En otras palabras, la buena fe impondría al errans renunciar al derecho a impetrar a la acción de nulidad por error, posibilidad que nuestro Código admite al consagrar el principio de la renunciabilidad de derechos en el artículo 12, exigiendo dos requisitos que concurren en la especie: que la renuncia de este derecho no esté probibida y ella mire al solo interés del renunciante. En efecto, lo que se prohíbe es la renuncia anticipada de la nulidad en el artículo 1459, porque ella protege los intereses superiores de la colectividad y en la adaptación del contrato por error unilateral estamos precisamente en la hipótesis opuesta, pues el contratante renuncia a demandar la nulidad cuando ya ha incurrido en el error. De otro lado, evidentemente la adaptación mira al interés individual del errans, pues, como lo hemos venido reiterando, le permite alcanzar la satisfacción de su interés por vía directa, sin más dilación o demora.

Podría pensarse que un argumento adicional para abogar por la adaptación del contrato sería que la renuncia a demandar la nulidad relativa está expresamente permitida en el Código Civil, por medio de la figura de la confirmación, regulada entre los artículos 1693 y 1697. De hecho, ambas comparten los mismos fundamentos, cuales son la renunciabilidad de los derechos y el principio del favor contractus, pero se trata de figuras diversas, pues en aquella el vicio se sanea y el contrato original se valida; en la

${ }^{60}$ Sobre la noción de abuso del derecho de opción y sus elementos véase López, P.V., "El abuso del derecho de opción del acreedor y su importancia en la construcción de un sistema equilibrado de remedios por incumplimiento contractual", en Revista Chilena de Derecho Privado, No 19, Santiago, diciembre, 2012, pp. 13-62.

${ }^{61}$ Morales, A., El error..., op. cit., p. 88. 
adaptación, en cambio, renunciar a alegar la nulidad acarrea como consecuencia que el contrato original sea reemplazado por su versión adaptada o modificada.

Resuelta la interrogante relativa a la adaptación del contrato por error unilateral, nos resta indagar si es posible sostener su procedencia a propósito del error compartido. Nuevamente nos inclinamos por la respuesta afirmativa, toda vez que, ambos contratantes, deberán renunciar a demandar la nulidad por error, de modo que resultan plenamente aplicables los argumentos que hemos invocado para sustentar la admisibilidad de la adaptación del contrato por error unilateral, esto es, la medida del interés del errans, el principio de la renunciabilidad de los derechos al que alude el artículo 12 de nuestro Código Civil y la buena fe contractual consagrada en dicho cuerpo normativo.

El problema que se presenta en este caso no es su admisibilidad, sino la forma en que ella debe efectuarse. En principio, podría pensarse que, como los artículos 4:105 (2) de los PECL y II.-7:203 (2) del DCFR exigen al juez adaptar el contenido del contrato, otorgándole el sentido que razonablemente hubieran acordado las partes sino hubiera existido error, debe recurrirse al contrato para extraer el criterio de adaptación. Pero como lo indicamos a propósito del caso del cuadro que se atribuía a un artista desconocido y que en realidad pertenecía a uno famoso, puede que no exista parámetro objetivo en el contrato para ajustarlo equitativamente, debiendo ponderar el juez los valores ofrecidos por ambos contratantes y cotejarlos con el valor de mercado para arribar a una solución justa.

De allí que se sostenga que la modelación judicial de la adaptación del contrato en el error compartido ofrece mayores dudas y que, por lo mismo, no se haya incorporado en las Propuestas de modernización españolas, como lo revelan los artículos 1298.4 de la PME y 527-14 de la PAPDC. Miradas las cosas desde esta perspectiva, resulta poco probable que nuestros tribunales admitan una solicitud de adaptación, porque han sido reacios a acoger la teoría de la imprevisión o alteración sobrevenida de las circunstancias $^{62}$, pese a que su procedencia se ha argumentado contundentemente ${ }^{63}$, invocando al efecto la intangibilidad del contrato, a partir del tenor del artículo 1545 del Código Civil, aduciendo que este no puede ser alterado, sino por voluntad de las partes, toda vez

${ }^{62}$ Excepcionalmente ha sido acogida por la Corte de Apelaciones de Santiago en sentencia de 14 de noviembre de 2006 y por la Corte de Apelaciones de San Miguel el 20 de enero de 2011. Un análisis de estas sentencias en Alcalde, E., "Corte de Apelaciones de Santiago y Teoría de la Imprevisión. Un hito fundamental en la evolución de nuestra justicia ordinaria.: Guillermo Larraín Vial con Servicio de Vivienda y Urbanización de la Región Metropolitana. Corte de Apelaciones de Santiago 14 de noviembre de 2006", en Revista Chilena de Derecho, Vol. 34, No 2, 2007, pp. 361-372, Momberg, R., "Análisis crítico desde el derecho alemán y nacional de una sentencia de la Corte de Apelaciones de Santiago que acoge la teoría de la imprevisión”, en Guzmán, A. (ed. científico), Estudios de Derecho Civil III, Editorial LegalPublishing, Santiago, 2008, pp. 650-657, López, J., Los Contratos. Parte General, Editorial AbeledoPerrot LegalPublishing, Santiago, 2010, $5^{\text {a }}$ ed. actualizada por Fabián Elorriaga De Bonis, pp. 263-266 y Pizarro, C., “¿Hay espacio para la revisión contractual por excesiva onerosidad sobrevenida? Los vaivenes de la imprevisión en la judicatura”, en Gaceta Jurídica No 369, Santiago, 2011, pp. 16-20.

${ }^{63}$ López, J., op. cit., pp. 259-260. 
que los jueces no tienen más facultades que las que expresamente se les han otorgado, $y$, entre ellas, no se encuentra la de modificar convenciones ${ }^{64}$.

Sin embargo, al igual que en el caso de la imprevisión, parece equitativo desligarse del principio del pacta sunt servanda ${ }^{65}$, con el propósito de restablecer el equilibrio contractual originario, más aún si las partes están de acuerdo que este debe adaptarse y facultan al juez para que la efectúe. Por lo mismo, la adaptación judicial del contrato por error compartido, pactada convencionalmente a la época de celebrar el contrato o sobrevenida con posterioridad, constituye una alternativa altamente conveniente para preservar el contrato y satisfacer el interés que tuvieron las partes al momento de contratar y que, como consecuencia del doble error, no quedó plasmado en él.

\section{CONFlUENCIA ENTRE LA ADAPTACión PRECONTRACTUAL Y CONTRACTUAL:}

\section{LA OPCIÓN DEL ACREEDOR Y EL ALCANCE DE AMBAS TUTELAS}

Delimitados los contornos de la adaptación como medio de tutela precontractual, es posible preguntar si ella puede confluir con la contractual, pues tal constatación será útil para dilucidar cuál de ellas otorga una protección más efectiva al acreedor en el evento que pueda optar entre ambas. La primera estaría integrada por el error vicio compartido o unilateral y la lesión enorme, existiendo solo parámetros objetivos para determinar el monto a reducir en esta última hipótesis. En tanto la segunda comprende la rebaja del precio en su acepción amplia, esto es, como medio de tutela por incumplimiento, y la imprevisión, supuesto en que la ejecución se torna sobrevenidamente más onerosa.

Atendidos los diferentes requisitos de procedencia de una y otra tutela es difícil que un mismo hecho determine la procedencia de ambas, pues si bien ellas se activan con la ruptura del equilibrio prestacional, en la precontractual este es originario, en tanto en la contractual es funcional. Dicho de otra forma, tendrían que darse dos supuestos: a) que el error vicio implicara a la vez un cumplimiento defectuoso de la prestación o un cumplimiento oneroso sobrevenido o b) que el desequilibrio prestacional asociado a la lesión enorme coincidiera con una inejecución imperfecta de la prestación o una alcanzara un costo excesivo. En definitiva, debe existir una asimetría relevante que pueda situarse a la vez en la fase precontractual y contractual, lo que no tiene lugar tratándose de la imprevisión, toda vez que, en tal caso, el desequilibrio encuentra su causa en un caso fortuito o fuerza mayor y no en la situación de inferioridad o en el error en que ha incurrido uno de los contratantes. Dicho desequilibrio tampoco confluiría en un supuesto

${ }^{64}$ Por todos, Abeliuk, R., Las Obligaciones. Tomo II, Editorial Jurídica de Chile, $3^{\text {a }}$ ed., Santiago, 1993 , pp. 705-706.

${ }^{65}$ Véase Momberg, R., "La revisión del contrato por las partes: el deber de renegociación como efecto de la excesiva onerosidad sobreviniente”, en Revista Chilena de Derecho, Vol. 37, N 1, pp. 67 y 68. 
de error vicio y rebaja del precio, toda vez que el grado de diligencia que se exige en el primero es mediana, en tanto, en la segunda es mínima ${ }^{66}$.

Por consiguiente, en el único caso que parece presentarse tal confluencia es tratándose de la lesión enorme y la rebaja del precio, sea que se abogue por una noción objetiva de la primera y estricta de la segunda o se acuñe una noción amplia de la primera y se postule la procedencia general de la segunda y aun cuando difieran en sus presupuestos, fase contractual en que tienen cabida y ámbito de aplicación. Y es que en la lesión enorme la reducción de la prestación excesiva procede por un desequilibrio que se manifiesta en una desproporción aritmética cuyo antecedente es la necesidad o situación de inferioridad de uno de los contratantes; en cambio, en la rebaja del precio esa asimetría encuentra su causa en el vicio grave, oculto y preexistente a la época de celebración del contrato -si se adhiere a una noción estricta- o en la prestación defectuosa -en el evento que se acoja una noción amplia ${ }^{67}$. De otro lado, la primera resulta procedente en todo contrato bilateral del que emane una prestación susceptible de ser reducida por cumplimiento imperfecto de la contraparte derivada de una prestación defectuosa, a diferencia de lo que ocurre con la rebaja de la prestación excesiva por lesión enorme, que tendría cabida tratándose de actos unilaterales e incluso respecto de actos aleatorios en la medida que sea posible valorar el riesgo y, por tanto, la proporcionalidad de las prestaciones ${ }^{68}$.

En lo que concierne al binomio noción objetiva de lesión/noción estricta de rebaja del precio, piénsese en el comprador agricultor que paga más de la mitad del justo precio que el inmueble tenía al tiempo del contrato y este adolece de una composición química que solo le permite construir sobre él bodegas y cultivar dos de cuatro clases de hortalizas que exporta. En tanto, en lo que respecta al binomio noción amplia de lesión/noción amplia de rebaja del precio, sirva de ejemplo el supuesto en que un instructor de yoga exige como pago de sus servicios un precio que supere en más de la mitad al que corresponde según el mercado y tal servicio fuere, además, deficiente.

Lo cierto es que el alcance de las tutelas, en uno y otro caso es diverso. En efecto, tratándose de la lesión enorme en sentido amplio el monto a reducir debe calcularse de conformidad a la fórmula que hemos enunciado precedentemente, esto es, todo aquello que excede el cincuenta por ciento del valor de la prestación convenida o del interés

${ }^{66}$ De Verda, J. R., Saneamiento por vicios ocultos. Las acciones edilicias, $2^{\mathrm{a}}$ ed., Editorial Aranzadi Thomson Reuters, Navarra, 2009, pp. 243-248.

${ }^{67}$ Dicha noción constituye la moderna tendencia en el derecho comparado. Una visión panorámica en Ferrante, A., La reducción del precio en la compraventa, Cizur Menor: Thomson Reuters-Aranzadi, Navarra, 2012, pp. 127-133, López, P.V., "El principio de equilibrio contractual..., op. cit., pp. 153-155 y, recientemente, la Ordenanza N 2016-131 de 10 de febrero de 2016 que modificó el Code.

${ }^{68}$ Así se desprende de los postulados formulados por alguna dogmática comparada (Papayannis, D., "La lesión subjetiva-objetiva en el derecho argentino", en Revista Lecciones y Ensayos, $\mathrm{N}^{\circ}$ 81, diciembre, 2005, pp. 87-88 y Alberruche Díaz-Flores, M. M., La Rescisión por Lesión en el Derecho Civil Español. Madrid, Editorial La Ley, Madrid, 2010, pp. 260 y 511), de sentencias de nuestros tribunales que se ha pronunciado en este sentido, la ausencia de norma expresa que la prohíba respecto este tipo de actos en nuestro Código (López, P.V., "Por una noción amplia de Lesión Enorme...", op. cit., pp. 711-714) y la amplitud con que es recogida esta figura en el soft law. 
correspondiente. En cambio, en la rebaja del precio el método de cálculo dependerá de la fórmula que contemple cada ordenamiento jurídico, distinguiéndose el método de resta y el método proporcional puro y, a falta de ella, como ocurre en nuestro Código Civil, aquella que la doctrina y la jurisprudencia estimen más correcta. El primero identifica el precio de compra con el valor objetivo del bien, aun cuando pueden no coincidir, desestabilizando el equilibrio que se quiere restablecer, particularmente en los casos en que se entrega un aliud pro alio, se realiza una compra inferior al valor de mercado o se oferta un bien a un precio inferior al del mercado. El método proporcional puro, en tanto, considera el precio estipulado del bien y la disminución de sus funcionalidades, debiendo cuantificarse el monto a disminuir necesariamente por medio de un peritaje ${ }^{69}$. Con todo, cualquiera sea el método que se adopte o se sigan los criterios de proporcionalidad, gravedad del vicio o los costos de reparación de la cosa ${ }^{70}$, ninguno de ellos equivale al monto de la reducción de la prestación excesiva derivada de la existencia de lesión enorme, pues no contemplan como, regla general, una fórmula única e invariable, que consista en reducir todo aquello que exceda de la mitad de la prestación convenida o de los intereses pactados ${ }^{71}$.

Sin embargo, nada impide que, en los supuestos que venimos examinando, el acreedor pueda acumular ambas reducciones, toda vez que sus fundamentos y presupuestos son diversos, de modo que no existiría un enriquecimiento sin causa. Es más, la entidad independiente de ellas nos permite constatar una especial preocupación del legislador por ampararlo frente a desproporciones prestacionales inequitativas, restableciendo el equilibrio alterado por diferentes causas, tanto en sede precontractual como contractual, advirtiéndose así una coherencia en el estatuto protector de ambos sistemas de tutela mediante la adaptación del contrato, aunque las reducciones, como lo evidencian los métodos de cálculo de cada una de ellas, sean de una entidad diversa.

${ }^{69}$ En lo que concierne a los métodos de cálculo de la rebaja del precio Ferrante, A., La reducción del precio..., op. cit., pp. 183-304 y pp. 267-269.

70 Acerca de los métodos de cálculo adoptados por los distintos Códigos Civiles, Prado, P., op. cit., pp. 631-638. A partir de los criterios seguidos en el derecho comparado la autora examina la jurisprudencia nacional y constata que se ha reducido una cantidad determinada o un porcentaje sobre el precio acordado, proponiendo como posibles criterios la proporcionalidad, la gravedad del vicio y el costo de reparación del bien (Ibid., pp. 639-646).

${ }^{71}$ La excepción se encuentra en la regla del artículo 1890, aplicable a la compraventa de inmuebles, y según lo dispuesto por el artículo 1900, a la permuta de aquellos. Dicho precepto señala que, si el comprador contra el cual se pronuncia la rescisión decide mantener el contrato, deberá completar el justo precio con la deducción de la décima parte; el vendedor, en cambio, deberá restituir el exceso del precio recibido sobre el justo precio, aumentado en una décima parte. Sobre el origen de dicho precepto Walker, N., "Derecho de opción del contratante vencido en juicio por lesión enorme. Orígenes e interpretación del artículo 1890 del Código Civil”, Revista chilena de derecho, Vol. 39, No 2, 2012, pp. 297-312. 


\section{Conclusiones}

De lo expuesto precedentemente, es posible arribar a las siguientes conclusiones:

1. La adaptación del contrato es un medio de tutela precontractual que tiene por objeto la mantención del contrato y procede en aquellos casos de excesiva desproporción y error común o compartido, siempre que ella sea conveniente y aún posible, permitiéndole al contratante perjudicado satisfacer directamente su interés, ampliando el ámbito de procedencia del principio del favor contractus en esta sede, mediante una figura diversa a la confirmación de la nulidad y evidenciando que esta última no constituye el único medio de tutela en dicha fase, sino el más radical.

2. Es posible concebir como primera modalidad de adaptación del contrato en sede precontractual, la lesión enorme, sea que solo se acoja su procedencia en los casos expresamente regulados en nuestro Código Civil o se abogue por una noción amplia, proyectándola más allá de esas hipótesis en la modalidad rebaja de la prestación excesiva, toda vez que, en ambos supuestos, constituye una manifestación del equilibrio contractual originario o congénito orientada prevalentemente a tal propósito.

3. Una segunda modalidad de adaptación del contrato se advierte tratándose del error vicio unilateral o compartido, debido a que si bien el Código Civil establece como único efecto de este la nulidad relativa, no existe óbice para que los contratantes se inclinen por la adaptación del contrato en la medida que esta sea conveniente y aún posible. Así lo revelan el principio de renunciabilidad de los derechos, pues faculta a uno o a ambos para renunciar a la acción de nulidad, y el principio de buena fe que imponen al errans el deber de aceptar la adaptación ofrecida por el otro en la medida que esta permita satisfacer su interés.

4. Eventualmente podría existir un desequilibrio que se sitúe, a la vez, en la fase precontractual y contractual, tratándose de la lesión enorme y la rebaja del precio, sea que se postule una noción objetiva o amplia de la primera o se acuñe una estricta o general de la segunda, lo que permitirá al perjudicado no solo optar entre ellas, sino acumularlas, develando una especial preocupación del legislador por ampararlo frente a desproporciones inequitativas y advirtiéndose una coherencia entre ambos sistemas de tutela, aunque estas reducciones sean de una entidad diversa.

\section{BiBLIOGRAFÍA}

Abeliuk Manasevich, R., Las Obligaciones. Tomo II, Editorial Jurídica de Chile, $3^{\mathrm{a}}$ ed., Santiago, 1993.

Alessandri, A., La nulidad y la rescisión en el derecho civil chileno, Tomo II, Editorial Jurídica de Chile, $3^{\mathrm{a}}$ ed., Santiago, 2008.

Alessandri Rodríguez, A.; Somarriva Undurraga, M.; Vodanovic Haklicka, A., Tratado de derecho civil: parte preliminar y parte general. Tomo II. $7^{\mathrm{a}}$ ed., Editorial Jurídica de Chile, Santiago, 2005. 
Alberruche Díaz-Flores, M. M., La Rescisión por Lesión en el Derecho Civil Español. Madrid, Editorial La Ley, Madrid, 2010.

Alcalde Rodríguez, E., "Corte de Apelaciones de Santiago y Teoría de la Imprevisión. Un hito fundamental en la evolución de nuestra justicia ordinaria.: Guillermo Larraín Vial con Servicio de Vivienda y Urbanización de la Región Metropolitana. Corte de Apelaciones de Santiago 14 de noviembre de 2006”, en Revista Chilena de Derecho, Vol. 34, N 2, 2007, pp. 361-372.

Alcalde Silva, J., "Bases para una sistematización de los efectos de la resolución por incumplimiento”, en Vidal, A.; Severin, G.; Mejías, C. (edits.), Estudios de Derecho Civil X, Editorial Thomson Reuters La Ley), Santiago, 2015, pp. 579-600.

BARAONA González, J., La nulidad de los actos jurídicos: consideraciones históricas y dogmáticas, Editorial Pontificia Universidad Javeriana-Ibáñez, Bogotá, 2012.

Barrientos Zamorano, M., Daños y deberes en las tratativas preliminares de un contrato, Santiago, Editorial LegalPublishing, 2008.

Barros Bourie, E., Tratado de responsabilidad civil extracontractual, Editorial Jurídica de Chile, Santiago, 2006.

Bosch Capdevila, E., "La anulación del contrato por explotación injusta en la Propuesta de Anteproyecto de Ley de Modernización del Derecho de Obligaciones y Contratos”, en Bosch, E. (dir.), Nuevas perspectivas del derecho contractual, Editorial Bosh, Barcelona, 2012, pp. 365-389.

CAMPBElL, D., Introduction: the function and structure of remedies for failure to perform a contractual obligation en Harris, D.; Campbell, D.; Halson, R., Remedies in Contract E Tort, University Press, second edition, Cambridge, 2005.

Carranza Álvarez, C., "Apuntes sobre la excesiva desproporción prestacional en el contrato. Una mirada a los Principios del UNIDROIT", Revista Colombiana de Derecho Internacional Pontificia Universidad Javeriana, No 4, 2004, pp. 379-402.

Carranza Álvarez, C., La presunción de aprovechamiento en la lesión contractual, Tesis de Magíster Pontificia Universidad Católica del Perú, 2012, disponible en sitio http://tesis.pucp.edu. pe/repositorio/bitstream/handle/123456789/4599/CARRANZA_ALVAREZ_CESAR_ LESION_CONTRACTUAL.pdf? sequence $=1$.

Celedón Förster, R.; Silberman Veszpremi, P., Responsabilidad precontractual por ruptura de negociaciones contractuales, Editorial Jurídica de Chile, Santiago, 2010.

Contardo González, J. I., Indemnización y resolución por incumplimiento, Editorial Thomson Reuters La Ley, Santiago, 2015.

Corral Talciani, H., Contratos y Daños por Incumplimiento, Editorial AbeledoPerrot LegalPublishing, Santiago, 2010.

Cuadrado Pérez, C. "La responsabilidad precontractual en la reforma proyectada: ¿una ocasión perdida? (parte II)”, Revista Crítica de Derecho Inmobiliario, N ${ }^{\circ} 746$, noviembre, 2015 , pp. 2999-3047.

Chantepie, G.; Latina, M., La réforme du droit des obligations. Commentaire théorique et practique dans l' ordre du Code Civil, Dalloz, Paris, 2016.

De la Maza Gazmuri, I. "Libertad y seguridad: el tratamiento del error en los Principios de Derecho Contractual Europeo", en Revista Chilena de Derecho, Vol. 34, N 3, diciembre, 2007, pp. 495-515.

De la Maza Gazmuri, I., "Tipicidad y atipicidad de los deberes precontractuales de información”, en Revista de Derecho Pontificia Universidad Católica de Valparaíso, Vol. 34, julio, 2010, pp. 75-99. 
De la Maza Gazmuri, I., "El suministro de información como técnica de protección de los consumidores: los deberes precontractuales de información", en Revista de Derecho Universidad Católica del Norte, año 17, $\mathrm{N}^{\circ} 2,2010$, pp. 21-52.

De la Maza Gazmuri, I. "Las consecuencias de la alteración sobrevenida de las circunstancias", en Figueroa, G., Barros, E., Tapia, M., Estudios de Derecho Civil VI, Editorial AbeledoPerrot LegalPublishing, Santiago, 2011, pp. 297-320.

De la MaZa Gazmuri, I., "El error vicio del consentimiento: Entre la protección y el aprovechamiento", en Elorriaga, F. (coord.), Estudios de Derecho Civil VII, Editorial AbeledoPerrot LegalPublishing, Santiago, 2012, pp. 511-523.

De la MaZa Gazmuri, I., "El error en los Principios Latinoamericanos de Derecho de los Contratos", en Vaquer, A.; Bosch, E.; Sánchez, M. P. (edits.), El derecho común europeo de la compraventa y la modernización del derecho de contratos, Editorial Atelier, Barcelona, 2015, pp. 789-799.

De Verda y Beamonte, J. R., Saneamiento por vicios ocultos. Las acciones edilicias, $2^{\mathrm{a}}$ ed., Editorial Aranzadi Thomson Reuters, Navarra, 2009.

Deshayes, O.; Genicon, T.; Laithier, Y. M., Reforme du droit des contracts, du régimen générale et de la prevue des obligations. Comentaire article par article, Lexis Nexis, 2016.

Díez-Picazo, L., Fundamentos del Derecho Civil Patrimonial I. Introducción Teoría del Contrato, $6^{a}$ ed., Editorial Civitas, Madrid, 2007.

Díez-PICAzo, L., Roca Trías, E. y Morales Moreno, A., Los Principios del Derecho Europeo de Contratos, Editorial Civitas, Madrid, 2002.

Domínguez Benavente, R.; Domínguez Águila, R., Derecho Sucesorio. $3^{\mathrm{a}}$ ed. actualizada, Editorial Jurídica de Chile, Santiago, 2011.

Ferrante, A., La reducción del precio en la compraventa, Cizur Menor: Thomson Reuters-Aranzadi, Navarra, 2012.

Ferrante, A., "¿Quimera o Fénix? El recorrido europeo y latinoamericano hacia un derecho común de contratos”, en Revista de Derecho Privado, Universidad Externado de Colombia, Vol. 30, 2016, enero-junio, pp. 107-127.

GaSPAR Lera, S., "Formación de la voluntad contractual, vicios del consentimiento y remedios", en Parra, M.A., Negociación y perfección de los contratos, Editorial Thomson Reuters Aranzadi, Navarra, 2014, pp. 369-315.

Ginés Castellet, N., "La ventaja o explotación injusta en el ¿futuro? Derecho contractual”, Indret Privado 4, 2016, octubre, en http://www.indret.com/pdf/1264_es.pdf (consultada el 5 de enero de 2017).

Lando, O.; Beale, H., Principios de derecho contractual europeo. Partes I y II (Traducc. Pilar Barres Benlloch, José Embid Irujo, Fernando Martínez Sanz), Colegios Notariales de España, Madrid, 2003.

López Díaz, C., Revisión de los contratos por causas sobrevinientes, Editorial Metropolitana, $3^{\mathrm{a}}$ ed., Santiago, 2014.

López Díaz, P.V, "El abuso del derecho de opción del acreedor y su importancia en la construcción de un sistema equilibrado de remedios por incumplimiento contractual", en Revista Chilena de Derecho Privado, No 19, Santiago, diciembre, 2012, pp. 13-62.

López Díaz, P.V., La autonomía de la indemnización de daños por incumplimiento de un contrato bilateral en el Código Civil Chileno, Editorial Thomson Reuters LegalPublishing, Santiago, 2015, pp. 344-356.

López Díaz, P.V., "Por una noción amplia de Lesión Enorme en el Código Civil Chileno: una relectura a partir del principio de equilibrio contractual y la idea de excesiva desproporción contenida en el Borrador de los Principios Latinoamericanos de derecho de los contratos", en 
Vidal, A.; Severin, G.; Mejías, C., Estudios de Derecho Civil X, Editorial Thomson Reuters, La Ley, Santiago, 2015, pp. 699-723.

López Díaz, P.V., "El principio de equilibrio contractual en el Código Civil chileno y su particular importancia como fundamento de algunas instituciones del moderno derecho de las obligaciones en la dogmática nacional”, en Revista Chilena de Derecho Privado, $\mathrm{N}^{\circ} 25$, diciembre, 2015, pp. 115-181.

López Díaz, P.V., "Por la articulación de un sistema de medios de tutela precontractual en el Código Civil chileno", en Estudios de Derecho Civil XII, en prensa.

López Díaz, P.V., "Los supuestos y el alcance de la indemnización de daños como medio de tutela precontractual en el Código Civil chileno y su eventual confluencia con la indemnización por incumplimiento", en Revista Ius et Praxis, en prensa.

López Santa María, J., Los Contratos. Parte General, Editorial AbeledoPerrot LegalPublishing, Santiago, 2010, $5^{\mathrm{a}}$ ed. actualizada por Fabián Elorriaga De Bonis.

Martín Pérez, J.A., La rescisión del contrato: en torno a la lesión contractual y el fraude de los acreedores, Editorial Bosh, Barcelona, 1995.

Mejías Alonzo, C.C., "Una revisión crítica de los efectos de la resolución por incumplimiento y una propuesta de solución”, Revista Ius et Praxis año 22, No 1 (2016), pp. 271-322.

Moisset de Espanes, L., La lesión en los actos jurídicos, Dirección General de Publicaciones de la Universidad Nacional de Córdoba, Córdoba, 1979.

Momberg Uribe, R., "Análisis crítico desde el derecho alemán y nacional de una sentencia de la Corte de Apelaciones de Santiago que acoge la teoría de la imprevisión”, en Guzmán, A. (editor científico), Estudios de Derecho Civil III, Editorial LegalPublishing, Santiago, 2008, pp. 637-657.

Momberg Uribe, R., "La revisión del contrato por las partes: el deber de renegociación como efecto de la excesiva onerosidad sobreviniente", en Revista Chilena de Derecho, Vol. 37, No 1 , pp. 43-72.

Momberg Uribe, R., "El rol de la publicidad en la etapa precontractual de los negocios de consumo y su relación con el principio de buena fe", en Corral, H.; Rodríguez, M. (edits.), Estudios de Derecho Civil II, Editorial Lexis Nexis, Santiago, 2007, pp. 593-608.

Momberg Uribe, R., Teoría de la imprevisión: la necesidad de su regulación legal en Chile, Revista Chilena de Derecho Privado No 15, diciembre, 2010, pp. 29-64.

Momberg Uribe, R., "La reformulación del rol del juez en los instrumentos contemporáneos de derecho contractual”, Revista de Derecho Universidad Católica del Norte, año 21, No 2, 2014 , pp. 277-304.

Morales Moreno, A., El error en los contratos, Editorial Ceura, Madrid, 1988.

Morales Moreno, A., "Validez del Contrato" en: Cámara, S. (coord.), Derecho Privado Europeo, Editorial Colex, Madrid, 2003, pp. 371-397.

Morales Moreno, A., “¿Es posible construir un sistema precontractual de remedios? Reflexiones sobre la Propuesta de Modernización del Derecho de Obligaciones y Contratos en el marco del Derecho europeo", en Albiez, K. (dir.), Palazón, M. L. y Méndez, M.M. (coords.), Derecho Privado Europeo y Modernización del Derecho Contractual en España, Editorial Atelier, Barcelona, 2011, pp. 400-422.

Neme Villareal, M. L., "El error como vicio del "consentimiento" frente a la protección de la confianza en la celebración del contrato, Revista de Derecho Privado Universidad Externado de Colombia, No 22, enero-junio, 2012, pp. 169-218.

PANTAleón, F., "Responsabilidad precontractual: propuestas de regulación para un futuro Código Latinoamericano de Contratos”, en Anuario de Derecho Civil, Vol. 64, No 3, 2011, pp. 897-929. 
Papayannis, D., "La lesión subjetiva-objetiva en el derecho argentino", en Revista Lecciones y Ensayos, $\mathrm{N}^{\circ}$ 81, diciembre, 2005, pp. 71-113.

Peñallillo Árevalo, D., "La revisión judicial de obligaciones y contratos en la reforma del Código Civil (La lesión y la imprevisión)", en Revista de Derecho Universidad de Concepción, año 68, No 208, 2000, pp. 209-237.

Pinochet Olave, R. y Concha Machuca, R., "Las prestaciones mutuas en caso de nulidad de contrato: carácter indemnizatorio o restitutorio en el derecho civil chileno", en Revista de Derecho Privado Universidad Externado de Colombia, Vol. 28, enero-junio, 2015, pp. 129-152.

PinOchet Olave, R., "Obsolecencia programada y protección del derecho a la información en la Ley N 19.496 de Protección de los Consumidores”, en Vidal, A.; Severin, G.; Mejías, C., Estudios de Derecho Civil X, Editorial Thomson Reuters, La Ley, Santiago, 2015, pp. 397-411.

Pizarro Wilson, C., “¿Hay espacio para la revisión contractual por excesiva onerosidad sobrevenida? Los vaivenes de la imprevisión en la judicatura", en Gaceta Jurídica No 369, Santiago, 2011, pp. 16-20.

Pizarro Wilson, C., "Contra el efecto retroactivo de la resolución por incumplimiento contractual”, en Elorriaga, F. (coord.), Estudios de Derecho Civil VII, Editorial AbeledoPerrot LegalPublishing Thomson Reuters, Santiago, 2012, pp. 449-460.

Prado López, P., "La cuantificación de la rebaja del precio en la acción quanti minoris", en Revista Ius et Praxis, año 21, $\mathrm{N}^{\circ} 1$, junio, 2015, pp. 617-650.

Rodríguez Grez, P., Inexistencia y nulidad en el Código Civil. Teoría Bimembre de la Nulidad, Editorial Jurídica de Chile, Santiago, 1995.

RodríGuez Pinto, M.S., "Responsabilidad precontractual en la Ley 19.496 de 1997 sobre Protección de los Derechos de los Consumidores", en Domínguez, C.; González, J.; Barrientos, M.; Goldenberg, J., Estudios de Derecho Civil VIII, Editorial LegalPublishing, Santiago, 2013, pp. 493-501.

Rosende Álvarez, H., Algunas consideraciones sobre la responsabilidad precontractual, Ediciones Universitarias de Valparaíso, Valparaíso, 1979.

UNIDROIT, Instituto Internacional para la Unificación del Derecho Privado, en Garro, A. (dir.), Rodríguez Olmos, J.M; Perales Viscasillas, P. (cols.), Principios UNIDROIT sobre los contratos comerciales internacionales, Ediciones UNIDROIT, Madrid, 2010.

Walker Silva, N., "Derecho de opción del contratante vencido en juicio por lesión enorme. Orígenes e interpretación del artículo 1890 del Código Civil”, Revista chilena de derecho, Vol. 39, No 2, 2012, pp. 297-312.

Zuloaga, I.M., Teoría de la responsabilidad precontractual. Aplicaciones en la etapa de la formación del consentimiento, Editorial LexisNexis, Santiago, 2006. 
